\title{
The Influence Of Higher Moments And Non-Normality On The Sharpe Ratio: A South African Perspective
}

Dr. Chris van Heerden, North-West University, South Africa

\begin{abstract}
Although the general assumption is that daily and monthly return data are normally distributed (Aparicio \& Estrada, 2001), the correct statistical distribution of returns must first be established (Linden, 2001), as it constitutes one of the elementary building blocks that will ensure accurate financial analyses (Taylor, 1986). The assumption of normality is also critical when constructing reference intervals for variables (Royston, 1991). By evaluating the pre-, during and post-20072009 financial crisis periods, this paper found that non-normality can be present in all data frequencies, especially in higher data frequencies. Further evidence also illustrated that the deviation from normality escalated over the crisis period and remained higher after the crisis, compared to the pre-crisis period. By comparing the traditional Sharpe ratio with adjusted versions, based on Gatfaoui's (2012) methodology, this paper accentuates that the presence of non-normality and higher moments can influence the Sharpe ratio's performance rankings.
\end{abstract}

Keywords: Emerging Market; Higher Moments; Normality; Sharpe Ratio

\section{INTRODUCTION}

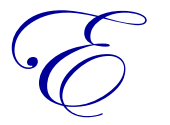

merging markets tend be more exposed to shocks which are induced by events, such as exchange rate devaluations, regulatory changes, political and global economic crises (SARB, 2010; Bekaert, Erb, Harvey \& Viskanta, 1998). Even so, emerging markets are generally associated with high expected returns and lower correlation with other markets, making it a desirable option to promote greater portfolio diversification (Bekaert, Erb, Harvey \& Viskanta, 1998). This emphasise the necessity to identify suitable investment options in emerging markets by means of a performance evaluation process. However, critical findings suggest that the traditional mean-variance analysis approach will not be suitable, as emerging market returns can have significant kurtosis and skewness (Bekaert, Erb, Harvey \& Viskanta, 1998). This argument is emphasised by Hentati, Kaffel and Prigent (2010), who stated that one the greatest criticisms of the standard mean-variance analysis approach is that it ignores the higher moments, and that variance will, therefore, provide a flawed perception of actual risk (Harlow, 1991). This implies that traditional performance measures, like the Sharpe ratio, will tend to overestimate the real risk inherent in the asset classes under evaluation (Brooks \& Kat, 2002). Also, very different portfolio allocations will be possible, with the presence of non-normal returns, when comparing the traditional mean-variance framework to more advanced performance measures (see for example; Wong, Phoon \& Lean, 2008; Cvitanić, Lazrak, Martellini \& Zapatero, 2003; Lamm, 2003; Popova, Morton \& Popova, 2003; Terhaar, Staub \& Singer, 2003; Fung \& Hsieh, 1999). Additionally, the study by Harris and Mazibus (2010) argued that volatility modelling can assist investors in improving portfolio allocation and performance. However, due to the presence of fat tails within return distributions, several volatility models have been found to be inconsistent in describing the empirical features of equity indices or option prices (see for example Chernov, Ghysels, Gallant \& Tauchen, 2003; Eraker, Johannes \& Polson, 2003; Andersen, Benzoni \& Lund, 2002; Bates, 2000; Bakshi, Cao \& Chen, 1997). Other fundamental analyses have also examined the statistical distributions of traditional financial ratios and have found that these ratios may provide bias information if not adjusted for the presence of non-normality (see for example Nikkinen \& Sahloström, 2004; Mcleay \& Omar, 2000; Deakin, 1976; Horrigan, 1965). Overall, these findings emphasise the importance to refrain from assuming that returns are normally distributed, as it can lead to inaccurate results and unsuccessful investment decisions. 
Furthermore, evidence suggested that the characteristics of emerging market returns tend to change drastically with the occurrence of market transformation, where a market moves from a state of segmentation to a state of integration (Bekaert \& Harvey, 2000; 1997; 1995; Bekaert, Erb, Harvey \& Viskanta, 1998). This implies that the fundamental source of risk can also change as market transformation occurs (Bekaert \& Harvey, 2000; 1997; 1995), making global economic circumstances a more vital contributor to anticipated risk (volatile returns). For example, the 2007-2009 financial crisis made insurable profitable investment decisions more difficult as market volatility tends to increase during crisis periods (Karunanayake, Valadkhani \& O’brien, 2010; Schwert, 1989). This can have significant consequences for investors, where traditional performance measures, like the Sharpe ratio, will find it difficult to rank more volatile returns (Lo, 2002). Market transformation will also affect the skewness and kurtosis of the market returns, where greater market integration will imply greater market liquidity (Bekaert, Erb, Harvey \& Viskanta, 1998), which can lead to flawed performance rankings.

In addition, as information does not always arrive linearly at the market and investors do not always react immediately to the arrival of new information, it further accentuates the improbability of returns being normally distributed. In both instances, the market returns will tend to exhibit a leptokurtic (fat tailed) distribution (Aparicio \& Estrada, 2001), implying that traditional performance measures, which is based on the standard deviation and beta as a risk measure, will generate bias rankings. This necessitates the importance of correctly characterising a market's return distribution over certain time horizons and over different data frequencies, as this will guide investors to consult performance measures or volatility measures that are more applicable to the type of return distribution present. The goal of this paper is, therefore, not to determine the type of return distribution present, but to show that the distribution of returns can impact the efficacy of a traditional risk-adjusted performance measure.

The objectives are, firstly to determine if the return distribution characteristics of several South African investments, which will be considered as proxies for suitable emerging market investment options, have changed over the 2007-2009 financial crisis period. This will include the evaluation of the higher moments and the level of normality. If non-normality is present it will imply that traditional performance measures, which incorporates the standard deviation or beta as a risk component, will provide bias results that can lead to different portfolio allocations (see for example Amin \& Kat, 2003; Brooks \& Kat, 2002). Secondly, this paper will determine how the return distribution characteristics differ between different data frequencies over the pre-, during and post-financial crisis periods. Finally, to further emphasise these objective this paper will also set out to prove that different riskadjusted performance rankings will be possible with the presence of non-normality and higher moments and when evaluating different data frequencies. The traditional Sharpe ratio (Sharpe, 1966) will be consulted to generate several sets of performance rankings. The first set will be based on the proxies that are predominantly non-normally distributed during a specific time period for all three different frequencies, which will be confirmed by five different normality tests. This will be compared to a second set of rankings that are based on a normally generated version of the same non-normally distributed series, while the mean and standard deviation are held constant. This will allow an evaluation to illustrate the impact of higher moments on the traditional Sharpe ratio's performance rankings. The rational of this process is based on the notion that traditional performance measures fail to capture higher moments, which limit their ranking abilities (Amin \& Kat, 2003; Kat, 2003). Also, the possibility of downside surprise can be prevented (Lamm, 2003), which traditional risk denominators fail to capture. In order to further emphasise the effect of higher moments, the traditional Sharpe rankings, generated from the non-normal returns, will be compared to scaled Sharpe rankings that are based on Gatfaoui's (2012) methodology, which adjust for the presence of higher moments (skewness \& kurtosis).

The investment options that will be evaluated as proxies will include the returns of several South African equity indices, individual shares from the JSE Top 40 index, several short- and long-term bonds yields (capital market), money market rates, and several FOREX market rates. In order to achieve these objectives this paper will commence by elaborating on the methodology of normality and the variety of tests available (Section 2). Section 3 will continue by discussing risk-adjusted performance measures, which will focus on their weaknesses and the recommended adjustments for the traditional Sharpe ratio (Section 3). This will be followed by a discussion of the data and method in Section 4, where the empirical results will be reported in Section 5. The concluding remarks and recommendations will continue in Section 6. 


\section{METHODOLOGY OF NORMALITY}

In probability theory, the Gaussian distribution (or normal distribution or Gaussian bell curve) is a continuous probability distribution, which illustrates the probability of a number falling between any two real numbers and can be formulated as follows (Gauss, 1809; Whittaker \& Robinson, 1924):

$f(x)=\frac{1}{\sigma \sqrt{2 \pi}} e^{-\frac{(x-\mu)^{2}}{2 \sigma^{2}}}$

where $-\infty<x<+\infty ; \mu$ denotes the expectation of the distribution or the mean; $\sigma$ denotes the standard deviation; and $\sigma^{2}$ denotes the variance. From Equation 1 it is apparent that a normal distribution is completely dependable on the mean $(\mu)$ and variance $\left(\sigma^{2}\right)$. This implies that if $\mu=0$ and $\sigma=1$ then the distribution is considered to be a unit normal distribution, where a random variable with this distribution will be called a standard normal deviate (Steyn, Smit, Du Toit \& Strasheim, 1998). Although, if the normality assumption is violated the interpretations and inferences of some statistical procedures can become unreliable and invalid (Razali \& Wah, 2011), which further stresses the importance of establishing the presence of normality. There are several different numerical tests available, which can be categorised under five different assortments, which are based on the Chi-squared $\left(\chi^{2}\right)$, the empirical distribution function (EDF), moments, correlation and on entropy, respectively (Arshad, Rasool \& Ahmad, 2003; Wong \& Sim, 2000). The latter assortment of normality tests mentioned, which includes entropy based tests, such as the Vasicek tests (Vasicek, 1976) and the Van Es test (Van Es, 1992) will be excluded from this paper due to the limitations of current available statistical software packages. In the first assortment, the Pearson's $\chi^{2}$ test (Pearson, 1900) was one of the first normality tests to be developed, which can be formulated as follows (Tarongi \& Camps, 2010; Yazici \& Yolacan, 2007):

$\chi^{2}=\sum_{i=1}^{c} \frac{\left(O_{i}-E_{i}\right)^{2}}{E_{i}}$,

where $O_{i}$ denotes the observed values; and $E_{i}$ denotes the expected values within each of the categories $(c)$, all summed together. However, a key weakness of the $\chi^{2}$ test entails that the sample size must be large enough to ensure reliability and accuracy. Though, several studies have proposed possible solutions for the minimum size problem of the expected value (see for example Conover, 1980; Cochran, 1952). There is also no exact rule for the minimum size of the expected values $\left(E_{i}\right)$ in the $\chi^{2}$ test estimation (Overholt, 2013) and the test can lose power due to the loss of information caused by grouping (Arshad, Rasool \& Ahmad, 2003). Nonetheless, due to the $\chi^{2}$ test's versatility and simplicity it is still being applied by present researchers, although evidence have signified the superiority of normality tests which are based on the EDF and on correlation (see for example Razali \& Wah, 2011; Stephens, 1977; 1974;), which is why the $\chi^{2}$ test will not be applied in this paper.

The second assortment of normality tests under investigation includes the tests based on the EDF. Given $N$ ordered values of a sample $X$, the EDF can be illustrated as follows (Tarongi \& Camps, 2010):

$\widehat{F}_{N}(x)=\frac{\#\left\{X_{i} \backslash X_{i} \leq x\right\}_{\forall i=1 \ldots N}}{N}=\frac{1}{N} \sum_{i=1}^{N} I\left(X_{i} \leq x\right)$,

where $\widehat{F}_{N}(x)$ denotes the step function that increases by $\frac{1}{N}$ at the value of each ordered data point; $I(\cdot)$ denotes the indicator of the event; and $X_{i}$ denotes the $i^{t h}$ element of the sample to be evaluated, where the values must be ordered from lowest to highest. One of the first normality tests in this assortment to be developed includes Kolmogorov's normality test (Kolmogorov, 1933). This classic normality test compares the EDF of a sample to the cumulative distribution function (CDF) of the null distribution. However, the problem with this classic EDF test are that prior knowledge of the null distribution's parameters are required in order to estimate the normality test, which is why this test will be excluded from this paper. Though, with the development of the asymptotic theory and Monte Carlo studies the critical values for the composite versions of this test can be calculated (D'Agostino \& Stephens, 1986). 
Alternative EDF normality tests, which will also form the focus point of this paper, include the Kolmogorov-Smirnov (KS) tests (Kolmogorov, 1933; Smirnov, 1939), the Cramér-von Misses' (CVM) criterion (Mises, 1931; Cramér, 1928), the Anderson-Darling $(A D)$ test (Anderson \& Darling, 1952), and the Lilliefors $(L)$ test (Lilliefors, 1967). According to Arshad, Rasool and Ahmad (2003), the $K S$ test, the $A D$ test and the CVM test are the most important EDF tests. The study of Stephens (1981) also proved that the $A D$ test is the most powerful EDF test, followed by the CVM test and the $K S$ test, respectively. The $K S$ test correlates the EDF with the normal distribution function, where the mean and variance must be a known parameter (Tarongi \& Camps, 2010), and can be formulated as follows (Yazici \& Yolacan, 2007):

$K S=\max \left\{D^{+}, D^{-}\right\}$

where $D^{+}$measures the upper difference between the EDF and the standard normal cumulative distribution function $[\Phi(x)]$; and $D^{-}$measures the lower difference between the EDF and $\Phi(x)$. The $K S$ test will consider the largest positive difference and the largest negative distance, in absolute terms, between the EDF and the $\Phi(x)$ as the test statistic (Overholt, 2013). Furthermore, the $K S$ test has two assumptions regarding the data series under investigation. Firstly, the data must be from a random sample, which is a similar assumption to that of the $\chi^{2}$ test. Secondly, only continuous data can be applied to the $K S$ test, whereas any type of data can be applied to the $\chi^{2}$ test. Moreover, the $K S$ test must have a fully specified hypothesised distribution to compare it with, where this paper will measure it against a standard normal distribution. Nonetheless, evidence suggests that the $K S$ test has the ability to outperform other modern alternatives (in terms of power) with small samples (Overholt, 2013; Seier, 2002). Though, it is argued $K S$ test may not be as powerful as tests specifically designed to test for normality (Öztuna, Elhan \& Tüccar, 2006). Additionally, as the mean and variance is not always known, and in order to avoid the errors that can be introduced with the estimating of a wrong variance, the Lilliefors $(L)$ test (Lilliefors, 1967; Tarongi \& Camps, 2010) can be consulted additionally, with the $K S$ test as a reference point. With the $L$ test the mean and variance of the normal distribution are obtained from the sample $X$ (Lilliefors, 1967). The $L$ test can be formulated as follows (Tarongi \& Camps, 2010):

$L=\max _{1 \leq i \leq N}\left|F\left(Y_{i}\right)-\hat{F}\left(X_{i}\right)\right|$,

where $\hat{F}\left(X_{i}\right)$ denotes the value of the $i^{\text {th }}$ element of the EDF of $X$; and $F\left(Y_{i}\right)$ is the value of the $i^{t h}$ element of the normal distribution function, with the mean $(\bar{Y})$ and variance $\left(\sigma_{Y}^{2}\right)$ equal to (Tarongi \& Camps, 2010):

$\bar{Y}=\frac{1}{N} \sum_{i=1}^{N} X_{i}$

$\sigma_{Y}^{2}=\frac{1}{N-1} \sum_{i=1}^{N}\left(X_{i}-\bar{X}\right)^{2}$,

where $N$ denotes the number of observations; and $\bar{X}$ the sample mean of $X$. The $L$ confidence values are obtained from the CDF of the $L$ test results, when applied to a normal distribution (Lilliefors, 1967). Due to the fact that the data are standardised, regardless of the mean and variance, the $L$ test is capable of detecting normality of any, even unspecified, normal distribution. However, the $L$ test faces some limitations in terms of the process used to derive the critical values table for this test. The test statistics of the $L$ test do not follow any known distribution, which implies that simulations, such as Monte Carlo simulations must be used to approximate the unknown distributions (Overholt, 2013). Furthermore, the $L$ test tends to be more sensitive near the centre of the distribution compared to the tails (Tarongi \& Camps, 2010). In order to overcome this shortcoming, the Anderson-Darling test $(A D)$ will also be consulted in this paper, which gives more weight to the tails (by including a weight function) compared to the $L$ test. See also the studies of Thadewald and Buning (2007) and of Balakrishnan, Chimitova, Galanova \& Vedernikova (2013) who highlight the superiority of the $A D$ test over other normality tests.

In addition, the $A D$ test is based on the comparison of distribution functions, which implies that the values of the sample to be evaluated must be ordered. The study of Anderson and Darling (1952) proposed the weighting function $\left[\psi(x)=(x(1-x))^{-1}\right]$, which will yield the statistic (Tarongi \& Camps, 2010; Thode, 2002): 
$A D^{* 2}=-N-\frac{1}{N} \sum_{i=1}^{N}(2 i-1)\left(\ln \Phi\left(Y_{i}\right)+\ln \left(1-\Phi\left(Y_{N+1-i}\right)\right)\right)$,

where $Y_{i}=\frac{X_{i}-\bar{X}}{\sigma_{X}} ; \Phi(\cdot)$ denotes the standard normal CDF operator. Furthermore, $A D^{* 2}$ must be adjusted for the sample size as follows (D'Agostino \& Stephens, 1986):

$A D^{2}=A D^{* 2}\left(1+\frac{0.75}{N}+\frac{2.25}{N^{2}}\right)$.

The critical values can be consulted from the tables of D'Agostino and Stephens (1986), whereas an empirical development of the critical values for the normal case can be consulted in the study of Trujillo-Ortiz, Hernandez-Walls, Barba-Rojo and Castro-Perez (2007). Although, one of the problems of the $A D$ test is with the calculation of $\ln \Phi\left(Y_{i}\right)$ and $\ln \left(1-\Phi\left(Y_{N+1-i}\right)\right)$, because the value of $Y_{i}$ can be too close to 0 or 1 , which will cause the logarithm to tend to infinity, thus making the estimation of the test statistic difficult. This problem will occur with heavy-tailed distributions and large sample sizes (Archila, 2010), like for example with the evaluation of hedge funds. A further variation of the $L$ test, which will also be consulted in this paper, includes the Cramer-von Mises (CVM) test (Mises, 1931; Cramér, 1928), which originates from a family of tests that compares the squares of the differences between the EDF of a sample and the CDF, by estimating the following statistic (Archila, 2010):

$\omega^{2}=N \int_{-\infty}^{+\infty}\left[F_{N}(x)-F(x)\right]^{2} \psi(F(x)) d F(x)$,

where $\psi(F(x))$ is a weighting function. If $\psi(F(x))=1$ and $F(x)=\Phi(x)$ then $\omega^{2}$ is the CVM statistic for testing normality (Thode, 2002):

$C V M=\sum_{i=1}^{N}\left(\Phi\left(Y_{i}\right)-\frac{(2 i-1)}{2 N}\right)^{2}+\frac{1}{12 N}$

where the confidence values can be obtained from the same methodology as the $L$ test.

Although the above mentioned normality tests are highly favoured, none of these tests use higher moments (skewness and kurtosis) to differentiate between distributions. This leads to the discussion of the third assortment of normality tests, which include the Jarque-Bera $(J B)$ test (Jarque \& Bera, 1987) and the D'Agostino-Pearson test (D'Agostino \& Pearson, 1973). Though, current statistical packages do not always provide the ability of estimating the D'Agostino-Pearson test, which is why this test will not be considered in this paper. In terms of the moments used in the estimation of these normality tests, the skewness $(S)$ is a statistical parameter that is related to the asymmetry of the probability density function (PDF) of a random variable. The kurtosis $(K)$, on the other hand, is a statistical parameter that is related to the shape (flatness/peakedness) of the PDF of a random variable (Tarongi \& Camps, 2010). The third and fourth moments (skewness and kurtosis) can be formulated as follow, respectively (QMS, 2009):

$S=\frac{1}{N} \sum_{i=1}^{N}\left(\frac{X_{i}-\bar{X}}{\widehat{\sigma}}\right)^{3}$

$K=\frac{1}{N} \sum_{i=1}^{N}\left(\frac{X_{i}-\bar{X}}{\widehat{\sigma}}\right)^{4}$

where $\hat{\sigma}$ denotes an estimator for the standard deviation that is based on the biased estimation for the variance $\left(\hat{\sigma}=s t d \sqrt{\frac{(N-1)}{N}}\right)$. A normal (Gaussian) random variable will have a skewness of zero, assuming a zero-mean random process $x$, whereas a normal random variable will have a kurtosis of three, independently of its mean and variance (Tarongi \& Camps, 2010). Furthermore, a return distribution will exhibit a long right tail with a positive skewness and a long left tail with a negative skewness. Also, the distribution will be leptokurtic (peaked) with a kurtosis greater than three or will be platykurtic (flat) if the kurtosis is less than three (QMS, 2009). A negative kurtosis implies that the distribution can be more flat, have shorter tails, or both (Archila, 2010). Moreover, investments, 
usually hedge funds, which exhibit returns with a leptokurtic distribution and a negative skewness have the probability of carrying a downside surprise (see for example Lamm, 2003). This implies that the variance, standard deviation and beta will be unable to provide an actual perception of the risk involved, where these measures will only demonstrate how the positive returns will be penalised and not the level of 'hedge fund risk' involved (Kat, 2003; Harding, 2002). This further accentuates the importance of evaluating the higher moments of investment returns, as this will determine the applicability of consulting certain performance and risk measures during an investment decision. Nonetheless, the skewness and kurtosis coefficient have several disadvantages that must first be acknowledge. Firstly, both have an unbounded influence function and both have zero breakdown value, which imply that bias estimates could be generated with the presence of outliers. Secondly, both are only defined on distributions that have finite moments (Brys, Hubert \& Struyf, 2008).

In addition, the first normality test of the third assortment that will be consulted in this paper includes the Jarque-Bera $(J B)$ test, which is an asymptotic test that is based on Ordinary Least Square (OLS) residuals. This normality test makes use of the standardised skewness and kurtosis, which can be estimated as follows (Gujarati, 2006):

$J B=\frac{n}{6}\left[S^{2}+\frac{(K-3)^{2}}{4}\right]$

where $n$ is the sample size; $S$ denotes the skewness; and $K$ denotes kurtosis. The $J B$ test follows a $\chi^{2}$ distribution with 2 degrees of freedom asymptotically (Gujarati, 2006), which can lead to error measurements when the sample size is too small (Poitras, 2006; 1992; Dufour, Farhat, Gardiol \& Khalaf, 1998; Urzúa, 1996; Jarque \& Bera, 1987). Moreover, evidence suggests that normality testing that is dependent on robust residuals may outperform normality testing that is dependent on OLS residuals (Önder \& Zaman, 2005). Several studies have also suggested the use of modified versions of the $J B$ test can improve results, like for example the study of Brys, Hubert and Struyf (2008). Nonetheless, evidence has been found which illustrated that the $J B$ test gives the most powerful results for normal distributions (Öztuna, Elhan \& Tüccar, 2006). The study of Bradley and Morris (2013) also found that the $J B$ test and Edgeworth expansion of negentropy (Lin, Saito \& Levine, 1999) perform similarly.

Finally, the fourth assortment of normality tests are based on correlation and include the Shapiro-Wilk $(S W)$ test (Shapiro \& Wilk, 1965) and the D'Agostino test (D'Agostino, 1971), where the latter test will be excluded from this paper due to the limitations of current statistical packages. The $S W$ test that was proposed by Shapiro and Wilk (1965) can be formulated as follows (Farrell \& Rogers-Stewart, 2006):

$S W=\frac{\left(\sum_{i=1}^{n} a_{i} x_{i}^{2}\right)}{\sum_{i=1}^{n}\left(x_{i}-\bar{x}\right)^{2}}$

where $\bar{x}$ denotes the sample mean; the vector $a^{\prime}=q^{\prime} V^{-1} \sqrt{\left(q^{\prime} V^{-1} V^{-1} q\right)}$, with $q$ being the vector of expected values of standardised order statistics under normality, and $V$ denotes the corresponding covariance matrix (Farrell \& Rogers-Stewart, 2006). The superiority of the $S W$ test will have been confirmed by several studies, where Bradley and Morris (2013) found that the $S W$ test will outperform the $A D$ test, the $J B$ test and negentropy-based tests (Bradley \& Morris, 2013). Negentropy-based tests are usually applied to detect normality in source-separation problems that involves Independent Component Analysis (ICA). (See for example, Cover \& Thomas, 2006; Hyvärinen \& Oja, 2000). Further evidence also illustrated that the $S W$ test can be more superior for detecting departures from normality, especially for symmetric long-tailed distributions (Farrell \& Rogers-Stewart, 2006). Although, Yap and Sim (2011) found evidence that the $S W$ test had better power with symmetric short-tailed distributions compared to other normality tests. Also, the $J B$ test illustrated similar performance with symmetric long-tailed distributions, whereas the $A D$ test and the $S W$ test were found to be the most powerful normality tests with asymmetric distributions (Yap \& Sim, 2011).

\section{METHODOLOGY OF RISK-ADJUSTED PERFORMANCE MEASURES}

The mean-variance approach of Markowitz (Markowitz, 1952) is considered as one of the more traditional approaches which can assist investors in compiling an efficient portfolio. According to this approach, different 
assets are combined which minimise the variance for a given level of return. However, one of the greatest criticisms of the mean-variance approach is that it ignores the higher moments (Hentati, Kaffel \& Prigent, 2010). It is also argued that variance and standard deviation do not provide a consistent perception of actual risk (Harlow, 1991), especially if the divergence from normality becomes more apparent when the higher moments (skewness \& kurtosis) of the return distributions are taken into account (Kat, 2003). This implies that the standard deviation can easily be manipulated by seeking returns in "non-normal risks", like extreme liquidity and credit risk and volatility variation risks (Amenc, Martellini \& Sfeir, 2004:2). Moreover, variance and standard deviation do not differentiate between downside and upside risk, which will penalise positive returns (De Wet, Krige \& Smit, 2008; Harding, 2002). This emphasises the possibility of very different portfolio allocations, with the presence of non-normality returns, when comparing the traditional mean-variance framework to more advanced performance measures (see for example, Wong, Phoon \& Lean, 2008; Lamm, 2003; Popova, Morton \& Popova, 2003; Fung \& Hsieh, 1999).

Another popular performance evaluation measure to consider is the traditional Sharpe ratio (Sharpe, 1966; see Equation 20 below). Though, several studies recommended modified versions of the traditional Sharpe ratio in an attempt to replace the flawed standard deviation as a denominator. For example, the modified Sharpe ratio (Gregoriou \& Gueyie, 2003); the modified Value at Risk (MVaR) model (Favre \& Galeano, 2002); the Conditional Drawdown at Risk (CDaR) model; the Conditional Value at Risk (CVaR) model (Krokhmal, Palmquist \& Uryasev, 2002); the Cornish-fisher ratio (Liang \& Park, 2007); as well as the Polynomial Goal Programming process (PGP) used by Davies, Kat and Lu (2009). However, Value-at-Risk (VaR)-based measures are still flawed by its sensitivity to the underlying parameters and that the employed calculation method relies on risk factors being normally distributed (Van Dyk, Van Vuuren \& Heymans, 2014).

Additionally, the traditional Sharpe ratio also assumes that the returns of the individual security are uncorrelated with the mean portfolio returns, which can lead to misleading performance rankings in the process (Sharpe, 1994). Although, Lo (2002) suggests that the Sharpe ratio can be adjusted for autocorrelation, where the method can be formulated by Equation 17 below.

Sharpe ratio $=\frac{r_{s}-\bar{r}_{f}}{\sigma_{s}}$,

$\eta(q) S R=\frac{q}{\sqrt{q+2 \sum_{k=1}^{q-1}(q-k) \rho_{k}}}$,

where $r_{s}$ denotes the average returns of a security; $\bar{r}_{f}$ denotes the risk-free rate; $\sigma_{s}$ denotes the standard deviation of a security's returns; $S R$ is the traditional Sharpe ratio on a monthly basis, as estimated in Equation 16; $q=12$; and $\rho_{k}$ is the $k^{\text {th }}$ autocorrelation for returns.

Another shortcoming of the traditional Sharpe ratio is that it fails to take any benchmark/threshold of a fund into consideration to estimate the excess returns, making the evaluation of some portfolios difficult (Amenc, Martellini \& Sfeir, 2004). Different rankings are also possible for the same portfolio, as each investor has its own risk preference and will choose different risk-free rates as benchmark (required return). For example, the study of Copeland, Koller and Murrin (2000), Brigham and Ehrhardt (2005) and Samouilhan (2007) consider the 91-day Treasury Bill rate as an appropriate proxy for evaluating portfolio performance. However, other studies, such as Moolman and Du Toit (2005) and De Wet (2005) consider the R157 bond yield and the R150 bond yield more applicable, respectively. Alternative studies also suggest the use of alternative risk-free rates, such as the 10-year government bond yield (Copeland, Koller \& Murrin, 2000), whereas Botha (2007) and Favre-Bulle and Pache (2003) recommended applying the 3-month JIBAR rate and the 3-month LIBOR rate, respectively. Furthermore, despite the popularity of the Sharpe ratio one of the greatest criticism of this ratio is its lack of accounting for the effect of asymmetry (skewness) and the heaviness of the distribution tails (kurtosis), which can influence the validity of the standard deviation or beta as risk measures. These risk measure are flawed as they are based on return variances, which measures only the dispersion of returns around its historical average and penalises positive and negative deviations from the historical average in a similar manner, leading thus to a misperception of actual risk (Lhabitant, 2004). In order to account for skewness and kurtosis, Gatfaoui (2012) propose that the following 
adjustments must be made in order to estimate an adjusted (scaled) Sharpe ratio, which can be formulated as follow:

Scaled Sharpe ratio $1\left(S^{*}\right)=w_{-} \times \frac{e x_{-}}{\sigma_{S_{-}}}+w_{+} \times \frac{e x_{+}}{\sigma_{S_{+}}}$,

Scaled Sharpe ratio $2\left(S^{* *}\right)$

$$
=w_{-} \times \frac{r_{s}-\bar{r}_{f}}{\sigma_{s_{-}}}+w_{+} \times \frac{r_{s}-\bar{r}_{f}}{\sigma_{s_{+}}}
$$

where $w_{-}=n_{-} \div n$ and $w_{+}=n_{+} \div n$, with $n_{-}$and $n_{+}$denoting the number of observations below and above the mean of the security, $n$ denotes the total number of observations under investigation; $e x_{-}$denotes negative excess returns; $e x_{+}$denotes positive excess returns; $r_{s}$ denotes the average returns of a security (with $r_{s_{-}}$and $r_{s_{+}}$denoting the left-skewed and right-skewed returns, respectively); $\bar{r}_{f}$ denotes the risk-free rate; and $\sigma_{s}$ denotes the standard deviation of the security's returns (with $\sigma_{s_{-}}$and $\sigma_{s_{+}}$denoting the downside and upside deviations, respectively).

\section{DATA AND METHOD}

Daily, weekly and monthly closing prices will be evaluated (average closing prices were used with the weekly \& monthly data frequencies), spanning from January 2005 to the end of December 2013. This time span will also be used to evaluate if the 2007-2009 financial crisis had an effect on market return distribution characteristics. This will be accomplished by dividing this time span into three time periods, namely a pre-financial crisis period, a during financial crisis period and a post-financial crisis period. The pre-financial crisis period (period 1) spans from January 2005 to December 2006, whereas the during financial crisis period (period 2) spans from January 2007 to December 2009 and the post-financial crisis period (period 3) spans from January 2010 to December 2013. The time span of period 1 was limited due to the unavailability of capital market rates that are under investigation, which were only available from January 2005. Furthermore, the during financial crisis period (period 2) was carefully constructed to incorporate key events to ensure that the impact of the crisis can be evaluated effectively. Period 2 starts by incorporating the date when the Federal Home Loan Mortgage Corporation (Freddie Mac) announced that no more risky subprime mortgages and mortgage-related securities will be bought (27 February 2007). It also includes the event when Northern Rock was taken into state ownership by the Treasury of the United Kingdom (17 February 2008); the announcements of Lehman Brothers Holdings Incorporated filing for bankruptcy on 15 September 2008); and continues until after the announcement when president Obama signed the American Recovery and Reinvestment Act of 2009, which included a variety of tax cuts and spending measures that were intended to promote economic recovery in the United States.

The 33 South African investment options that will be evaluated include investment proxies from the equity market, money market, capital market, FOREX market and other types, like the 1-ounce Kruger Rand, as reported in Table 1. All the closing price data were collected from the McGregor BFA (2013) database. The individual shares that will be evaluated comprise out of the top 14 shares of the JSE Top 40 index, based on the market capitalisation of 11 July 2014.

The empirical study will commence by evaluating the two higher moments (skewness \& kurtosis) of each of the return series over different data frequencies to determine if distribution characteristics changed over the three time periods. The empirical study will then continue by establishing if the return distributions (with different data frequencies) exhibited normality/non-normality over the three time periods. This will be determined by consulting several normality tests, which are based on the empirical distribution function (EDF), moments and correlation, respectively, in order to generate more conclusive results. The normality tests that are based on the EDF will include the Kolmogorov-Smirnov (KS) tests with the Lilliefors correction, the Cramér-von Misses' $(C V M)$ test and the Anderson-Darling $(A D)$ test. The normality tests that will be consulted in this paper which are based on moments and correlation will entail the Jarque-Bera $(J B)$ test and the Shapiro-Wilk $(S W)$ test, respectively. These analyses will be conducted with the EViews 7 program (QMS, 2009) and the IBM ${ }^{\circledR}$ SPPS Statistics, version 22 program (IBM, 2013), respectively. 
Table 1: South African Investment Options Under Investigation

\begin{tabular}{|c|c|c|}
\hline \multicolumn{2}{|c|}{ EQUITY MARKET } & \multirow{2}{*}{ MONEY MARKET ${ }^{\#}$} \\
\hline \multicolumn{2}{|c|}{ Indices } & \\
\hline \multicolumn{2}{|l|}{ JSE All Share index (J203) } & 1-month JIBAR yields \\
\hline \multicolumn{2}{|l|}{ JSE Financial index (J580) } & 3-month JIBAR yields \\
\hline \multicolumn{2}{|l|}{ JSE Bank index (J835) } & 6-month JIBAR yields \\
\hline \multicolumn{2}{|l|}{ JSE Industrial index (J520) } & 9-month JIBAR yields \\
\hline \multicolumn{2}{|l|}{ JSE Top 40 index (J200) } & 12-month JIBAR yields \\
\hline \multicolumn{2}{|c|}{ Individual shares from the JSE Top 40 index } & \multirow{2}{*}{ CAPITAL MARKET* } \\
\hline Name $^{+}$ & Sector & \\
\hline SABMiller Plc. (SAB) & Consumer Staples & R157 bond rate \\
\hline BHP Billiton Plc. (BIL) & Materials & R186 bond rate \\
\hline Compagnie Financière Richemont (CFR) & Consumer discretionary & 1-to-3 year bond index \\
\hline Naspers Limited (NPN) & Communication & 3-to-7 years bond index \\
\hline MTN Group Limited (MTN) & Communication & Over 12 year bond index \\
\hline Sasol Limited (SOL) & Energy & \multirow{2}{*}{ FOREX MARKET } \\
\hline Anglo American Plc. (AGL) & Materials & \\
\hline Standard Bank Group Limited (SBK) & Financials & ZAR/USD exchange rate \\
\hline FirstRand Limited (FSR) & Financials & ZAR/EUR exchange rate \\
\hline Old Mutual Plc. (OML) & Financials & ZAR/GBP exchange rate \\
\hline Barclays Africa Group Limited (BGA) & Financials & \multirow{2}{*}{ Other } \\
\hline Sanlam Limited (SLM) & Financials & \\
\hline Aspen Pharmacare Holdings Limited (APN) & Health care & \multirow{2}{*}{ 1-ounce Kruger Rand (KR) } \\
\hline Anglo American Platinum Limited (AMS) & Materials & \\
\hline
\end{tabular}

Source: Compiled by author.

${ }^{+}$Note: Due to the unavailability of data for the required periods under investigation this paper was unable to evaluate the prime rate and the $91-$ day Treasury Bill rate as additional money market rates; the JSE Resources index; and British American Tobacco Plc., Glencore Plc. and Vodacom Group Limited as three of the individual shares of the JSE Top 40 index.

\# Note: The annual yields where converted to daily, weekly and monthly yields, respectively, in order to evaluate the descriptive statistics. This ensures that all the data under investigation are in the same format.

*Note: The annual yields to maturity of the bonds were converted to daily, weekly and monthly annualised yields before the empirical study commenced.

Finally, the performance ranking evaluation will continue with the proxies that are predominantly nonnormally distributed during a specific time period for all three different frequencies. This ranking evaluation will commence by generating normally distributed versions of these series by applying Equation 1 (see Section 2) and by keeping the mean and standard deviation constant. This will be followed by applying the traditional Sharpe ratio to both of the non-normal and normally distributed series, where the findings will illustrate how the presence of nonnormality and higher moments can influence performance rankings. These rankings will then be compared to scaled Sharpe rankings that are based on the non-normal return series (based on Equation 18 \& 19, respectively).

\section{RESULTS}

The first step of the empirical study is to evaluate the skewness and kurtosis of the different frequencies, as they can influence the creditability of the traditional Sharpe ratio. The results reported in Table 2 illustrate that there is a linear relationship between the average kurtosis and the frequency level. Daily data always exhibit a higher average kurtosis during all three time periods, including the entire sample period, compared to weekly and monthly frequencies. Also, Table 2 reports that the different series under investigation are on average leptokurtic (kurtosis greater than three), which emphasise the results found by Heymans and Van Heerden (2014). Furthermore, the results from Table 2 report a linear relationship between the skewness and the frequency level, which implies that daily data will exhibit a higher average skewness compared to weekly and monthly data. However, this linear relationship is absent during the financial crisis period, where monthly data illustrate a higher average skewness compared to weekly data. 
Table 2: Summary Of Four Moments (Averages Of 33 Investment Proxies)

\begin{tabular}{|l|c|c|}
\hline \multicolumn{1}{|c|}{ Sample } & Average Skewness & Average Kurtosis \\
\hline Entire sample (Daily frequency) & 1.690 & 89.439 \\
\hline Entire sample (Weekly frequency) & 0.068 & 8.128 \\
\hline Entire sample (Monthly frequency) & -0.090 & 4.602 \\
\hline Pre-financial crisis period (Daily frequency) & 0.934 & 19.884 \\
\hline Pre-financial crisis period (Weekly frequency) & 0.293 & 3.528 \\
\hline Pre-financial crisis period (Monthly frequency) & 0.257 & 3.048 \\
\hline During financial crisis period (Daily frequency) & 0.256 & 16.118 \\
\hline During financial crisis period (Weekly frequency) & -0.010 & 5.942 \\
\hline During financial crisis period (Monthly frequency) & -0.077 & 3.597 \\
\hline Post-financial crisis period (Daily frequency) & 0.181 & 4.886 \\
\hline Post-financial crisis period (Weekly frequency) & 0.168 & 3.904 \\
\hline Post-financial crisis period (Monthly frequency) & 0.025 & 3.862 \\
\hline
\end{tabular}

Source: Compiled by author.

Note: See Table A in the Appendix for the complete results.

Finally, it is interesting to note that higher frequency data tend to exhibit a more dominant presence of higher moments when evaluating the investment proxies individually (see Table A in the Appendix). Besides daily data, which tend to exhibit higher moments throughout the different frequencies and periods under investigation, the presence of higher moments is the greatest during the financial crisis period for both the weekly and monthly frequencies. Furthermore, the presence of higher moments is also more dominant during the post-financial crisis period compared to pre-financial crisis period (see Table A in the Appendix). These findings imply that financial analysts should still be cautious when consulting traditional risk-adjusted performance measures, as the higher moments will corrode the accuracy of the performance rankings. The effect of the higher moments is further emphasised by the results found by the Jarque-Bera test, which illustrates that the presence of non-normality is greater with daily data compared to weekly and monthly data (See Table A in the Appendix). The presence of nonnormality is further highlighted by four additional normality tests, which concur that the assumption that daily and monthly return data are normality distributed is flawed. All the different frequencies exhibit a certain presence of non-normality, with monthly data exhibiting the lowest presence of non-normality and daily data the highest. Also, all three frequencies exhibit the same trend, where the presence of non-normality increased during the crisis period and remained higher during the post-financial crisis compared to the pre-financial crisis period (See Table $3 \&$ Table A in the Appendix). 
Table 3: Summary Of Normality Tests

\begin{tabular}{|c|c|c|c|c|c|c|c|c|c|c|c|c|}
\hline & \multicolumn{4}{|c|}{ DAILY FREQUENCY } & \multicolumn{4}{|c|}{ WEEKLY FREQUENCY } & \multicolumn{4}{|c|}{ MONTHLY FREQUENCY } \\
\hline & $\begin{array}{c}\text { Entire } \\
\text { Sample }\end{array}$ & $\begin{array}{c}\text { Pre- } \\
\text { Crisis } \\
\text { Period }\end{array}$ & $\begin{array}{c}\text { During } \\
\text { Crisis } \\
\text { Period }\end{array}$ & $\begin{array}{l}\text { Post- } \\
\text { Crisis } \\
\text { Period }\end{array}$ & $\begin{array}{c}\text { Entire } \\
\text { Sample }\end{array}$ & $\begin{array}{c}\text { Pre- } \\
\text { Crisis } \\
\text { Period }\end{array}$ & $\begin{array}{c}\text { During } \\
\text { Crisis } \\
\text { Period }\end{array}$ & $\begin{array}{l}\text { Post- } \\
\text { Crisis } \\
\text { Period }\end{array}$ & $\begin{array}{c}\text { Entire } \\
\text { Sample }\end{array}$ & $\begin{array}{c}\text { Pre- } \\
\text { Crisis } \\
\text { Period }\end{array}$ & $\begin{array}{c}\text { During } \\
\text { Crisis } \\
\text { Period }\end{array}$ & $\begin{array}{l}\text { Post- } \\
\text { Crisis } \\
\text { Period }\end{array}$ \\
\hline $\begin{array}{c}\text { 1-month } \\
\text { JIBAR }\end{array}$ & No & No & No & No & No & No & No & No & No & No & No & No \\
\hline $\begin{array}{c}\text { 3-month } \\
\text { JIBAR }\end{array}$ & No & No & No & No & No & No & No & No & No & No & No & No \\
\hline $\begin{array}{l}\text { 9-month } \\
\text { JIBAR }\end{array}$ & No & No & No & No & No & No & No & No & No & No & No & No \\
\hline $\begin{array}{l}\text { 12-month } \\
\text { JIBAR }\end{array}$ & No & No & No & No & No & No & No & No & No & No & No & No \\
\hline R 157 & No & No & No & No & No & No & No & No & No & Yes & No & No \\
\hline R 186 & No & No & No & No & No & No & No & No & Yes & Yes & Yes & No \\
\hline $\begin{array}{l}\text { 1-to-3 year } \\
\text { bond index }\end{array}$ & No & No & No & No & No & No & No & No & No & Yes & No & No \\
\hline $\begin{array}{l}\text { 3-to-7 year } \\
\text { bond index }\end{array}$ & No & No & No & No & No & No & No & No & No & Yes & No & No \\
\hline $\begin{array}{l}12+\text { month } \\
\text { bond index }\end{array}$ & No & No & No & No & No & Yes & No & No & No & Yes & No & No \\
\hline $\begin{array}{l}\text { JSE All } \\
\text { Share }\end{array}$ & No & No & No & No & No & No & No & No & No & No & No & No \\
\hline JSE Top 40 & No & No & No & No & No & No & No & No & No & Yes & No & No \\
\hline JSE Bank & No & No & No & No & No & No & No & Yes & No & Yes & Yes & Yes \\
\hline $\begin{array}{c}\text { JSE } \\
\text { Financials }\end{array}$ & No & No & No & No & No & Yes & No & Yes & No & Yes & Yes & Yes \\
\hline $\begin{array}{c}\text { JSE } \\
\text { Industrials } \\
\end{array}$ & No & No & No & No & No & No & No & Yes & No & Yes & No & No \\
\hline AGL & No & No & No & No & No & No & No & Yes & No & Yes & Yes & Yes \\
\hline BIL & No & No & No & No & No & Yes & No & Yes & Yes & Yes & Yes & Yes \\
\hline CFR & No & No & No & No & No & Yes & No & Yes & No & No & No & No \\
\hline NPN & No & No & No & No & Yes & Yes & Yes & Yes & Yes & Yes & Yes & Yes \\
\hline OML & No & No & No & No & No & No & No & No & No & Yes & Yes & Yes \\
\hline SAB & No & No & No & No & No & No & Yes & Yes & No & Yes & Yes & Yes \\
\hline SBK & No & No & No & No & No & Yes & No & Yes & Yes & Yes & Yes & Yes \\
\hline SOL & No & No & No & No & No & Yes & No & Yes & No & Yes & No & No \\
\hline BGA & No & No & No & No & No & Yes & Yes & No & Yes & Yes & Yes & Yes \\
\hline SLM & No & No & No & No & No & Yes & Yes & No & Yes & Yes & Yes & Yes \\
\hline APN & No & No & No & No & No & No & No & No & No & Yes & Yes & Yes \\
\hline AMS & No & No & No & No & No & No & No & Yes & No & No & No & No \\
\hline ZAR/EUR & No & No & No & No & No & No & No & $\mathrm{No}$ & No & No & No & Yes \\
\hline ZAR/GBP & No & No & No & No & No & Yes & No & No & No & No & No & Yes \\
\hline ZAR/USD & No & No & No & No & No & Yes & No & No & No & Yes & No & Yes \\
\hline $\begin{array}{c}\text { Kruger } \\
\text { Rand }\end{array}$ & No & No & No & No & No & No & No & No & No & No & No & No \\
\hline
\end{tabular}

Source: Compiled by author.

Note: "Yes" implies that none of the five normality tests rejected the null hypothesis; "No" implies that at least one of the five normality tests rejected the null hypothesis.

Note: See Table A in the Appendix for the complete results.

Overall, from these results it is conclusive that higher moments and non-normality are present in all three different data frequencies and during all three time periods under investigation, including the entire sample period. There is also evidence which suggests that the characteristics of the different return distributions exhibited significant change during the financial crisis period, especially for the weekly and monthly data series, and poses a challenge for risk-adjusted performance evaluations even after the crisis period. This implies that the reliability of the traditional Sharpe ratio is doubtful, which can lead to misleading investment decisions. To confirm this argument, all the investment proxies with non-normal return distributions and high moments during the financial crisis period will be evaluated. The financial crisis period was chosen as it provides the most suitable settings to 
conduct this risk-adjusted performance evaluation, as the presence of higher moments and non-normality was found to be the greatest during this period. The investment proxies chosen entail the JSE All Share index, the JSE Top 40 index, Compagnie Financière Richemont (CFR), Sasol Limited (SOL), the ZAR/EUR exchange rate, the ZAR/GBP exchange rate, the ZAR/USD exchange rate, the 1-ounce Kruger Rand (KR). Finally, the R157 bond rate was chosen as the risk-free rate proxy, which is based on the study of Moolman and Du Toit (2005). To illustrate how the presence of non-normality and higher moments can lead to different Sharpe rankings, compatible normality distributed return series must be generated for each of the nine non-normally distributed investment proxies under investigation. By keeping the mean and standard deviation constant, a normally distributed series were generated for each of the proxies in the three different data frequencies (by applying Equation 1 from Section 2), which also do not suffer from higher moments, as reported in Table 4. The adequacy of these normally distributed series is confirmed by the five different normality tests, which is not reported in this paper.

Table 4: Descriptive Summary Of The Normal And Non-Normal Series Under Investigation

\begin{tabular}{|c|c|c|c|c|c|c|c|c|c|c|c|c|}
\hline & \multicolumn{6}{|c|}{ DAILY FREQUENCY } & \multicolumn{6}{|c|}{ WEEKLY FREQUENCY } \\
\hline & \multicolumn{4}{|c|}{ ORIGINAL NON-NORMAL SERIES } & \multicolumn{2}{|c|}{$\begin{array}{l}\text { NORMAL } \\
\text { SERIES }\end{array}$} & \multicolumn{4}{|c|}{$\begin{array}{c}\text { ORIGINAL } \\
\text { NON-NORMAL SERIES }\end{array}$} & \multicolumn{2}{|c|}{$\begin{array}{l}\text { NORMAL } \\
\text { SERIES }\end{array}$} \\
\hline & Mean & Std. Dev. & Skew. & Kurt. & Skew. & Kurt. & Mean & \begin{tabular}{|l} 
Std. Dev. \\
\end{tabular} & Skew. & Kurt. & Skew. & Kurt. \\
\hline R157 & $0.023 \%$ & $0.002 \%$ & 0.993 & 4.148 & -0.054 & 2.964 & $0.163 \%$ & $0.013 \%$ & 0.960 & 4.099 & -0.211 & 2.816 \\
\hline JSE All Share & $0.029 \%$ & $1.740 \%$ & 0.024 & 4.947 & 0.006 & 2.718 & $0.109 \%$ & $2.972 \%$ & -0.015 & 3.898 & 0.182 & 2.910 \\
\hline JSE Top40 & $0.031 \%$ & $1.897 \%$ & 0.080 & 4.946 & -0.025 & 2.913 & $0.114 \%$ & $3.204 \%$ & 0.056 & 4.144 & -0.124 & 2.831 \\
\hline CFR & $-0.030 \%$ & $2.565 \%$ & -4.277 & 65.321 & 0.021 & 2.905 & $-0.194 \%$ & $4.601 \%$ & -2.153 & 12.885 & 0.121 & 2.769 \\
\hline SOL & $0.058 \%$ & $2.803 \%$ & 0.329 & 5.169 & -0.040 & 2.842 & $0.197 \%$ & $4.618 \%$ & -0.345 & 4.666 & -0.044 & 2.627 \\
\hline ZAR/EUR & $0.019 \%$ & $1.332 \%$ & 2.187 & 30.345 & 0.010 & 2.997 & $0.104 \%$ & $1.934 \%$ & 0.399 & 4.925 & -0.182 & 2.481 \\
\hline ZAR/GBP & $-0.024 \%$ & $1.357 \%$ & 1.773 & 25.297 & 0.071 & 2.981 & $-0.070 \%$ & $2.069 \%$ & 0.226 & 4.816 & 0.192 & 2.502 \\
\hline ZAR/USD & $0.025 \%$ & $1.505 \%$ & 2.111 & 26.625 & 0.034 & 2.753 & $0.060 \%$ & $2.314 \%$ & 1.261 & 6.865 & -0.136 & 2.691 \\
\hline \multirow[t]{4}{*}{ Kruger Rand } & $0.103 \%$ & $2.098 \%$ & 0.234 & 7.165 & -0.044 & 2.901 & $0.407 \%$ & $2.648 \%$ & 0.684 & 5.108 & -0.027 & 2.840 \\
\hline & \multicolumn{6}{|c|}{ MONTHLY FREQUENCY } & & & & & & \\
\hline & \multicolumn{4}{|c|}{ ORIGINAL NON-NORMAL SERIES } & \multicolumn{2}{|c|}{$\begin{array}{l}\text { NORMAL } \\
\text { SERIES }\end{array}$} & & & & & & \\
\hline & Mean & $\begin{array}{l}\text { Std. } \\
\text { Dev. }\end{array}$ & Skew. & Kurt. & Skew. & Kurt. & & & & & & \\
\hline R157 & $0.705 \%$ & $0.057 \%$ & 1.000 & 3.823 & 0.128 & 2.185 & & & & & & \\
\hline JSE All Share & $0.496 \%$ & $5.576 \%$ & -1.228 & 4.695 & 0.035 & 2.315 & & & & & & \\
\hline JSE Top40 & $0.508 \%$ & $5.848 \%$ & -1.179 & 4.526 & 0.152 & 2.318 & & & & & & \\
\hline CFR & $-0.725 \%$ & $10.011 \%$ & -2.163 & 9.219 & -0.058 & 2.143 & & & & & & \\
\hline SOL & $0.700 \%$ & $7.643 \%$ & -0.816 & 4.484 & 0.115 & 2.641 & & & & & & \\
\hline ZAR/EUR & $0.538 \%$ & $4.163 \%$ & 0.843 & 4.432 & 0.043 & 2.515 & & & & & & \\
\hline ZAR/GBP & $-0.263 \%$ & $4.207 \%$ & 1.230 & 5.509 & 0.203 & 2.949 & & & & & & \\
\hline ZAR/USD & $0.299 \%$ & $5.181 \%$ & 1.824 & 9.498 & 0.406 & 2.205 & & & & & & \\
\hline Kruger Rand & $1.856 \%$ & $6.195 \%$ & 0.759 & 4.373 & -0.078 & 2.224 & & & & & & \\
\hline
\end{tabular}

Source: Compiled by author.

The next step of the empirical study is to provide a risk-adjusted performance comparison between the rankings generated from normally distributed returns and that of non-normally distributed returns. A traditional Sharpe ratio and a serial correlated adjusted (SC) Sharpe ratio were estimated for both of the normally and nonormally distributed proxies. Additionally, two scaled Sharpe ratio versions, based on the study of Gatfaoui (2012), were estimated on the non-normal proxies to further emphasise the effects of higher moments. From the results reported in Table 5 it is evident that the presence of higher moments and non-normality will have a significant influence on the rankings provided by the Sharpe ratio. There seems to be no linear relationship present between the Sharpe rankings that are based on the normally distributed and non-normally distributed returns, respectively. This is true for all three data frequencies, although, the only exception is with the non-normally daily data, where the rankings between the traditional Sharpe ratio, the serial correlated adjusted (SC) Sharpe ratio and the SC scaled Sharpe ratio $\left(\mathrm{S}^{* *}\right)$ did not differ. 
Table 5: Ranking Summary Of Different Sharpe Versions (During The Financial Crisis Period)

\begin{tabular}{|c|c|c|c|c|c|c|c|c|c|c|c|}
\hline \multicolumn{12}{|c|}{ NON-NORMAL SERIES (DAILY FREQUENCY) } \\
\hline \multicolumn{2}{|c|}{ Traditional Sharpe } & \multicolumn{2}{|c|}{ SC Adjusted Sharpe } & \multicolumn{2}{|c|}{ Scaled Sharpe (S*) } & \multicolumn{2}{|c|}{$\begin{array}{c}\text { SC Scaled } \\
\text { Sharpe }\left(\mathbf{S}^{*}\right)\end{array}$} & \multicolumn{2}{|c|}{ Scaled Sharpe $\left(\mathbf{S}^{* *}\right)$} & \multicolumn{2}{|c|}{$\begin{array}{c}\text { Sc Scaled } \\
\text { Sharpe }\left(\mathbf{S}^{* *}\right)\end{array}$} \\
\hline Ranking & Estimate & Ranking & Estimate & Ranking & Estimate & Ranking & Estimate & Ranking & Estimate & Ranking & Estimate \\
\hline SOL & -0.025 & SOL & -0.065 & ZAR/GBP & 0.052 & ZAR/GBP & 0.107 & SOL & -0.039 & SOL & -0.101 \\
\hline JSE Top 40 & -0.081 & JSE Top 40 & -0.138 & $\begin{array}{c}\text { Kruger } \\
\text { Rand }\end{array}$ & -0.032 & Kruger Rand & -0.048 & JSE Top 40 & -0.122 & $\begin{array}{c}\text { JSE Top } \\
40\end{array}$ & -0.207 \\
\hline $\begin{array}{l}\text { JSE All } \\
\text { Share }\end{array}$ & -0.084 & JSE All Share & -0.141 & ZAR/EUR & -0.062 & SOL & -0.141 & $\begin{array}{l}\text { JSE All } \\
\text { Share }\end{array}$ & -0.124 & $\begin{array}{l}\text { JSE All } \\
\text { Share }\end{array}$ & -0.209 \\
\hline ZAR/USD & -0.100 & ZAR/USD & -0.256 & SOL & -0.065 & JSE Top 40 & -0.150 & ZAR/USD & -0.172 & ZAR/USD & -0.439 \\
\hline ZAR/EUR & -0.153 & ZAR/EUR & -0.398 & JSE Top 40 & -0.068 & $\begin{array}{l}\text { JSE All } \\
\text { Share }\end{array}$ & -0.151 & ZAR/EUR & -0.247 & ZAR/EUR & -0.642 \\
\hline CFR & -0.495 & CFR & -1.039 & ZAR/USD & -0.068 & ZAR/EUR & -0.159 & ZAR/GBP & -0.744 & CFR & -1.867 \\
\hline ZAR/GBP & -0.614 & ZAR/GBP & -1.781 & $\begin{array}{l}\text { JSE All } \\
\text { Share }\end{array}$ & -0.069 & ZAR/USD & -0.173 & CFR & -0.890 & ZAR/GBP & -2.157 \\
\hline \multicolumn{2}{|c|}{$\begin{array}{c}\text { Traditional } \\
\text { Sharpe Ratio }\end{array}$} & \multicolumn{2}{|c|}{$\begin{array}{l}\text { SC Adjusted } \\
\text { Sharpe Ratio }\end{array}$} & \multicolumn{2}{|c|}{$\begin{array}{c}\text { Scaled Sharpe } \\
\text { Ratio }\left(\mathbf{S}^{*}\right)\end{array}$} & \multicolumn{2}{|c|}{$\begin{array}{c}\text { SC Scaled } \\
\text { Sharpe Ratio }\left(\mathbf{S}^{*}\right)\end{array}$} & \multicolumn{2}{|c|}{$\begin{array}{c}\text { Scaled Sharpe } \\
\text { Ratio }\left(\mathbf{S}^{* *}\right)\end{array}$} & \multicolumn{2}{|c|}{$\begin{array}{c}\text { SC Scaled Sharpe } \\
\text { Ratio }\left(\mathbf{S}^{* *}\right)\end{array}$} \\
\hline Ranking & Estimate & Ranking & Estimate & Ranking & Estimate & Ranking & Estimate & Ranking & Estimate & Ranking & Estimate \\
\hline $\begin{array}{c}\text { Kruger } \\
\text { Rand }\end{array}$ & 1.654 & $\begin{array}{c}\text { Kruger } \\
\text { Rand }\end{array}$ & 3.326 & CFR & 0.079 & CFR & 0.167 & Kruger Rand & 2.836 & $\begin{array}{c}\text { Kruger } \\
\text { Rand }\end{array}$ & 5.701 \\
\hline SOL & -0.229 & SOL & -0.628 & ZAR/GBP & 0.062 & ZAR/GBP & 0.122 & SOL & -0.343 & SOL & -0.941 \\
\hline JSE Top 40 & -0.437 & JSE Top 40 & -1.059 & $\begin{array}{c}\text { Kruger } \\
\text { Rand }\end{array}$ & -0.067 & ZAR/EUR & -0.094 & JSE Top 40 & -0.700 & $\begin{array}{c}\text { JSE Top } \\
40\end{array}$ & -1.698 \\
\hline $\begin{array}{l}\text { JSE All } \\
\text { Share }\end{array}$ & -0.462 & $\begin{array}{l}\text { JSE All } \\
\text { Share }\end{array}$ & -1.094 & ZAR/EUR & -0.071 & SOL & -0.103 & $\begin{array}{l}\text { JSE All } \\
\text { Share }\end{array}$ & -0.726 & $\begin{array}{l}\text { JSE All } \\
\text { Share }\end{array}$ & -1.720 \\
\hline ZAR/EUR & -0.574 & ZAR/EUR & -1.310 & SOL & -0.078 & ZAR/USD & -0.144 & ZAR/EUR & -0.959 & ZAR/EUR & -2.190 \\
\hline ZAR/USD & -0.757 & CFR & -1.444 & $\begin{array}{l}\text { JSE All } \\
\text { Share }\end{array}$ & -0.086 & Kruger Rand & -0.146 & ZAR/USD & -1.581 & ZAR/GBP & -2.506 \\
\hline CFR & -0.953 & ZAR/USD & -1.691 & JSE Top 40 & -0.089 & $\begin{array}{l}\text { JSE All } \\
\text { Share }\end{array}$ & -0.159 & ZAR/GBP & -1.982 & CFR & -3.274 \\
\hline \multicolumn{2}{|c|}{$\begin{array}{c}\text { Traditional } \\
\text { Sharpe Ratio } \\
\end{array}$} & \multicolumn{2}{|c|}{$\begin{array}{l}\text { SC Adjusted } \\
\text { Sharpe Ratio }\end{array}$} & \multicolumn{2}{|c|}{$\begin{array}{c}\text { Scaled Sharpe } \\
\text { Ratio }\left(\mathbf{S}^{*}\right)\end{array}$} & \multicolumn{2}{|c|}{$\begin{array}{c}\text { SC Scaled } \\
\text { Sharpe Ratio }\left(S^{*}\right)\end{array}$} & \multicolumn{2}{|c|}{$\begin{array}{c}\text { Scaled Sharpe } \\
\text { Ratio }\left(\mathbf{S}^{* *}\right)\end{array}$} & \multicolumn{2}{|c|}{$\begin{array}{c}\text { SC Scaled Sharpe } \\
\text { Ratio }\left(\mathbf{S}^{* *}\right)\end{array}$} \\
\hline Ranking & Estimate & Ranking & Estimate & Ranking & Estimate & Ranking & Estimate & Ranking & Estimate & Ranking & Estimate \\
\hline $\begin{array}{c}\text { Kruger } \\
\text { Rand }\end{array}$ & 0.573 & $\begin{array}{c}\text { Kruger } \\
\text { Rand }\end{array}$ & 1.300 & CFR & 0.283 & ZAR/GBP & 0.639 & $\begin{array}{c}\text { Kruger } \\
\text { Rand }\end{array}$ & 1.086 & $\begin{array}{c}\text { Kruger } \\
\text { Rand }\end{array}$ & 2.464 \\
\hline SOL & -0.136 & SOL & -0.199 & ZAR/GBP & 0.149 & CFR & 0.495 & SOL & -0.205 & SOL & -0.299 \\
\hline ZAR/EUR & -0.205 & JSE Top 40 & -0.396 & SOL & -0.044 & JSE Top 40 & 0.171 & JSE Top 40 & -0.356 & $\begin{array}{c}\text { JSE Top } \\
40\end{array}$ & -0.650 \\
\hline JSE Top 40 & -0.217 & $\begin{array}{l}\text { JSE All } \\
\text { Share }\end{array}$ & -0.415 & JSE Top 40 & -0.110 & SOL & 0.082 & $\begin{array}{l}\text { JSE All } \\
\text { Share }\end{array}$ & -0.359 & $\begin{array}{l}\text { JSE All } \\
\text { Share }\end{array}$ & -0.662 \\
\hline $\begin{array}{l}\text { JSE All } \\
\text { Share }\end{array}$ & -0.225 & ZAR/EUR & -0.471 & $\begin{array}{l}\text { JSE All } \\
\text { Share }\end{array}$ & -0.163 & $\begin{array}{l}\text { JSE All } \\
\text { Share }\end{array}$ & 0.008 & ZAR/EUR & -0.383 & ZAR/EUR & -0.881 \\
\hline ZAR/USD & -0.344 & ZAR/USD & -0.697 & ZAR/USD & -0.167 & ZAR/USD & -0.528 & ZAR/USD & -0.579 & ZAR/USD & -1.173 \\
\hline CFR & -0.628 & CFR & -0.912 & $\begin{array}{c}\text { Kruger } \\
\text { Rand }\end{array}$ & -0.257 & ZAR/EUR & -0.545 & ZAR/GBP & -0.971 & ZAR/GBP & -1.374 \\
\hline ZAR/GBP & -0.818 & ZAR/GBP & -1.157 & ZAR/EUR & -0.332 & Kruger Rand & -0.754 & CFR & -1.566 & CFR & -2.272 \\
\hline
\end{tabular}


(Table 5 continued)

\begin{tabular}{|c|c|c|c|c|c|c|c|c|c|c|c|}
\hline \multicolumn{4}{|c|}{ NORMAL SERIES (DAILY FREQUENCY) } & \multicolumn{4}{|c|}{$\begin{array}{c}\text { NORMAL SERIES (WEEKLY } \\
\text { FREQUENCY) }\end{array}$} & \multicolumn{4}{|c|}{$\begin{array}{l}\text { NORMAL SERIES (MONTHLY } \\
\text { FREQUENCY) }\end{array}$} \\
\hline \multicolumn{2}{|c|}{ Traditional Sharpe } & \multicolumn{2}{|c|}{ SC adjusted Sharpe } & \multicolumn{2}{|c|}{$\begin{array}{l}\text { Traditional } \\
\text { Sharpe ratio }\end{array}$} & \multicolumn{2}{|c|}{$\begin{array}{r}\text { SC adjusted } \\
\text { Sharpe ratio }\end{array}$} & \multicolumn{2}{|c|}{$\begin{array}{l}\text { Traditional } \\
\text { Sharpe ratio }\end{array}$} & \multicolumn{2}{|c|}{$\begin{array}{l}\text { SC adjusted } \\
\text { Sharpe ratio }\end{array}$} \\
\hline Ranking & Estimate & Ranking & Estimate & Ranking & Estimate & Ranking & Estimate & Ranking & Estimate & Ranking & \begin{tabular}{|l} 
Estimate \\
\end{tabular} \\
\hline $\begin{array}{l}\text { Kruger } \\
\text { Rand }\end{array}$ & 0.460 & $\begin{array}{l}\text { Kruger } \\
\text { Rand }\end{array}$ & 0.852 & $\begin{array}{l}\text { Kruger } \\
\text { Rand }\end{array}$ & 1.588 & Kruger Rand & 3.971 & $\begin{array}{l}\text { Kruger } \\
\text { Rand }\end{array}$ & 0.604 & $\begin{array}{l}\text { Kruger } \\
\text { Rand }\end{array}$ & 1.264 \\
\hline JSE Top 40 & -0.051 & JSE Top 40 & -0.071 & SOL & -0.242 & SOL & -0.354 & SOL & -0.166 & ZAR/EUR & -0.429 \\
\hline SOL & -0.059 & ZAR/USD & -0.182 & $\begin{array}{l}\text { JSE All } \\
\text { Share }\end{array}$ & -0.453 & $\begin{array}{c}\text { JSE All } \\
\text { Share }\end{array}$ & -0.917 & $\begin{array}{l}\text { JSE All } \\
\text { Share }\end{array}$ & -0.202 & \begin{tabular}{|c|} 
JSE Top \\
40
\end{tabular} & -0.438 \\
\hline $\begin{array}{l}\text { JSE All } \\
\text { Share }\end{array}$ & -0.093 & SOL & -0.186 & JSE Top 40 & -0.460 & JSE Top 40 & -1.284 & JSE Top 40 & -0.244 & $\begin{array}{c}\text { JSE All } \\
\text { Share }\end{array}$ & -0.546 \\
\hline ZAR/USD & -0.128 & $\begin{array}{c}\text { JSE All } \\
\text { Share }\end{array}$ & -0.286 & ZAR/EUR & -0.644 & ZAR/EUR & -1.707 & ZAR/EUR & -0.273 & SOL & -0.717 \\
\hline \begin{tabular}{|l} 
ZAR/EUR \\
\end{tabular} & -0.148 & ZAR/EUR & -0.427 & ZAR/USD & -0.800 & CFR & -2.319 & ZAR/USD & -0.341 & ZAR/USD & -0.754 \\
\hline CFR & -0.473 & ZAR/GBP & -0.899 & CFR & -0.917 & ZAR/USD & -2.519 & CFR & -0.574 & CFR & -1.568 \\
\hline \begin{tabular}{|l|l} 
ZAR/GBP \\
\end{tabular} & -0.643 & CFR & -1.419 & ZAR/GBP & -1.403 & ZAR/GBP & -3.222 & ZAR/GBP & -0.821 & ZAR/GBP & -1.680 \\
\hline
\end{tabular}

Source: Compiled by author.

It also seems that the presence of correlation increased in the weekly and monthly data, as the serial correlated adjusted (SC) Sharpe ratio tended to differ more from the rankings provided by the traditional Sharpe ratio. Furthermore, it is interesting to note that rankings seemed to differ even between different data frequencies, which are true for the rankings based on both normally and non-normally distributed returns. This possibility is emphasised by the results reported in Table A in the Appendix, which illustrated that all data frequencies possess a certain level of non-normality and higher moments and increase as the data frequency increases. These results, therefore, confirm the argument that the level of normality and the presence of higher moments will lead to different Sharpe rankings, which can ultimately leads to misleading and unprofitable investment decisions. Financial analysts should also be wary about the data frequency used to evaluate their investment decisions, as it can also lead to different performance rankings. It is, therefore, recommended that financial analysts and fund managers must always standardise their data in terms of frequency and adjust for higher moments in order to eliminate all discrepancies that can occur when benchmarking a fund or portfolio's performance.

\section{CONCLUSION AND RECOMMENDATIONS}

The general assumption is that daily and monthly return data are normally distributed, however, this paper has proven that this is not true for all markets. Evidence highlighted the fact that non-normal returns can be present in daily, weekly and monthly frequencies, although lower frequencies tended to exhibit less non-normal returns. This paper also illustrated that the return characteristics changed over the financial crisis period, where the presence of non-normality escalated in all data frequencies and remained higher during the post-financial crisis period compared to the pre-financial crisis period. This implies that financial analysts must still be wary about the adverse effect of non-normality and higher moments on risk-adjusted performance rankings, as it can lead to varying rankings. This argument was also proven, where the adjustment for higher moments and non-normality rendered different Sharpe rankings compared to rankings that are based on non-normal returns.

Overall, the conclusion can be made that monthly data are more preferable, as it tends to be more normally distributed compared to daily or weekly returns. Precaution is, however, still advised as all investment returns do not necessarily share the same characteristics, as proven in this paper. Note also that this paper has provided evidence which suggest that the data frequency can also have a significant effect on the rankings of investments. It is, therefore, advised that fund managers must always standardise their data in terms of frequency and adjust for higher moments in order to eliminate possible discrepancies that can occur when benchmarking a fund's performance.

To conclude, although the standard deviation or VaR-model variations are generally used as denominator in the Sharpe ratio, future studies are still required to provide better substitutes. A possible alternative may be to incorporate the Kalman filter (Kalman, 1960) to include a level of "future risk", which can overcome the general shortcoming of performance measures being backwards-looking. Furthermore, the greatest shortcoming of the Sharpe ratio is the use of a risk-free rate, which can differ depending on the investor's risk-preference, thus leading 
to different ranking possibilities. Future studies can focus on alternative approaches which can overcome this shortfall.

\section{AUTHOR INFORMATION}

\section{Dr. Chris van Heerden}

After completing his Masters in finance in 2008, Chris van Heerden was appointed as lecturer at the School of Economics, Potchefstroom Campus, North West University. Soon after he completed his PhD in finance in 2011, he was promoted to senior lecturer and is currently Program Head of Economics.

\section{RFERENCES}

1. Amenc, N., Martellini, L. \& Sfeir, D. (2004). Methodology applied for the AGEFI asset management awards. Working paper, the Edhec risk and asset management research centre.

2. Amin, G. S. \& Kat, H. M. (2003). Hedge fund performance 1990-2000: Do the "money machines" really add value? Journal of Financial and Quantitative Analysis, 38(2) 251-274.

3. Andersen,T., Benzoni,L. \& Lund, J. (2002).Towards an empirical foundation for continuous-time equity return models. Journal of Finance, 57(3) 1239-1284.

4. Anderson, T. W. \& Darling, D. A. (1952). Asymptotic theory of certain "goodness of fit" criteria based on stochastic processes. The Annals of Mathematical Statistics, 23(2) 193-212.

5. Aparicio, F.M. \& Estrada, J. (2001). Empirical distributions of stock returns: European securities markets, 1990-95. The European Journal of Finance, 7(1) 1-21.

6. Archila, F.H.A. (2010). A study of normality tests and an extension to the normality plot. Puerto Rico: University of Puerto Rico, Mayagüez campus. (Masters of science in mathematics statistics). 82p.

7. Arshad, M., Rasool, M.T. \& Ahmad, M.I. (2003). Anderson Darling and modified Anderson Darling tests for generalized pareto distribution. Pakistan Journal of Applied Sciences, 3(2) 85-88.

8. Bakshi, G., Cao, C. \& Chen, Z. (1997). Empirical performance of alternative option pricing models. Journal of Finance, 52(5) 2003-2049.

9. Balakrishnan, N., Chimitova, E., Galanova, N. \& Vedernikova, M. (2013). Testing goodness of fit of parametric AFT and PH models with residuals. Communications in Statistics - Simulation and Computation, 42(6) 1352-1367.

10. Bates, D. (2000). Post-' 87 crash fears in S\&P 500 futures options. Journal of Econometrics, 94(1-2) 181-238.

11. Bekaert, G. \& Harvey, C.R. (2000). Foreign speculators and emerging equity markets. Journal of Finance, 55(2) 565-613.

12. Bekaert, G., Erb, C.B., Harvey, C.R. \& Viskanta, T.E. (1998). Distributional characteristics of emerging market returns and asset allocation. The Journal of Portfolio Management, 24(2) 102-116.

13. Bekaert, G. \& Harvey, C.R. (1997). Emerging equity market volatility. Journal of Financial Economics, 43(1) 29-78.

14. Bekaert, G. \& Harvey, C.R. (1995). Time-varying world market integration. Journal of Finance, 50(2) 403444.

15. Botha, M. (2007). A comparison of South African hedge fund risk measures. South African Journal of Economics, 75(3) 459-477.

16. Brigham, E.F. \& Ehrhardt, M.C. (2005). Financial Management: Theory and practice, $11^{\text {th }}$ Edition. Mason, Ohio: Thomson South-Western. 1000p.

17. Brooks, C. \& Kat, H.M. (2002). The statistical properties of hedge fund index returns and their implications for investors. Journal of Alternative Investments, 5(2) 26-44.

18. Brys, G., Hubert, M. \& Struyf, A. (2008). Goodness-of-fit tests based on a robust measure of skewness. Computational statistics, 23(3) 429-442.

19. Chernov, M., Ghysels, E. Gallant, A.R. \& Tauchen, G. (2003). Alternative models for stock price dynamics. Journal of Econometrics, 116(1-2) 225-257.

20. Cochran, W.G. (1952). The $\chi^{2}$ test of goodness of fit. Annals of Mathematical Statistics, 23(3) 315-345.

21. Conover, W. J. (1980). Practical nonparametric statistics. $2^{\text {nd }}$ Edition. New York: Wiley. 493p.

22. Copeland, T., Koller, T. \& Murrin, J. (2000). Valuation: Measuring and managing the value of companies. 
$3^{\text {rd }}$ Edition. New York: Wiley. 490p.

23. Cover, T. M. \& Thomas, J. A. (2006). Elements of information theory. $2^{\text {nd }}$ Edition. Hoboken, NJ, USA: Wiley-Interscience. $748 \mathrm{p}$.

24. Cramér, H. (1928). On the composition of elementary errors. Scandinavian Actuarial Journal, 1928(1) 1374.

25. Cvitanić, J., Lazrak, A., Martellini, L., \& Zapatero, F. (2003). Optimal allocation to hedge funds: An empirical analysis. Quantitative Finance, 3(1) 28-39.

26. D'Agostino, R.B. (1971). An omnibus test of normality for moderate and large sample size. Biometrika, 58(2) 341-348.

27. D'Agostino, R. B. \& Pearson, E. S. (1973). Testing for departures from normality. Empirical results for the distribution of $b_{2}$ and $\sqrt{b 1}$. Biometrika, 60(3) 613-622.

28. D'Agostino, R. B. \& Stephens, M. A. (1986). Goodness-of-fit techniques. New York: Marcel Dekker. 560p.

29. Davies R.J., Kat H.M. \& Lu S. (2009). Fund of hedge funds portfolio selection: A multiple objective approach. Journal of derivatives and hedge funds, 15(2) 91-115.

30. Deakin, E.B. (1976). Distributions of financial accounting ratios: some empirical evidence. The Accounting Review, 51(1) 90-96.

31. De Wet, J. (2005). EVA versus traditional accounting measures of performance as drivers of shareholders value - a comparative analysis. Meditari: Research Journal of the School of Accounting Sciences, 13(2) 116.

32. De Wet, R., Krige, J.D. \& Smit, E. vd M. (2008). An investigation into performance rankings of the Omega ratio vs. the Sharpe ratio applied to South African general equity unit trusts. Journal of Studies in Economics and Econometrics, 32(2) 69-83.

33. Dufour, J., Farhat, A., Gardiol, L. \& Khalaf, L. (1998). Simulation-based finite sample normality tests in linear regressions. The Econometrics Journal, 1(1) 154-173.

34. Eraker, B., Johannes, M. \& Polson, N. (2003). The impact of jumps in volatility and returns. The Journal of Finance, 58(3) 1269-1300.

35. Farrell, P. J. \& Rogers-Stewart, K. (2006). Comprehensive study of tests for normality and symmetry: Extending the Spiegelhalter test. Journal of Statistical Computation and Simulation, 76(9) 803-816.

36. Favre, L. \& Galeano, J.A. (2002). Mean-Modified Value at Risk with hedge funds. The journal of alternative investments, 5(2) 21-25.

37. Favre-Bulle, A. \& Pache, S. (2003). The Omega measure: Hedge fund portfolio optimization. Canada: University of Lausanne. (MBF Master's Thesis).

38. Fleishman, A.I. (1978). A method for simulating non-normal distributions. Psychometrika, 43(4) 521-532

39. Fung, W. \& Hsieh, D. A. (1999). Is mean-variance analysis applicable to hedge funds? Economic Letters, 62(1) 53-58.

40. Gregoriou, G.N. \& Gueyie, J-P. (2003). Risk-adjusted performance of funds of hedge funds using a Modified Sharpe ratio. Journal of wealth management, 6(3) 77-83.

41. Gujarati, D.N. (2006). Essentials of econometrics. $3^{\text {rd }}$ Edition. New York: McGraw Hill. 553p.

42. Harding, D. (2002). A critique of the Sharpe Ratio. Working paper, the Winton capital management, United Kingdom.

43. Harlow, W.V. (1991). Asset allocation in a downside-risk framework. Financial Analysts Journal, 47(5) $28-40$.

44. Harris, R.D.F. \& Mazibus, M. (2010). Dynamic hedge fund portfolio construction. International Review of Financial Analysis, 19(5) 351-357.

45. Hentati, R., Kaffel, A. \& Prigent, J-L. (2010). Dynamic versus static optimization of hedge fund portfolios: The relevance of performance measures. International Journal of Business, 15(1) 1-17.

46. Heymans, A. \& Van Heerden, C. (2014). A risk-adjusted evaluation on the JSE Top 40 as an international investment option. Journal of Applied Business Research, 30(6), forthcoming.

47. Horrigan, J.O. (1965). Some empirical bases of financial ratio analysis. The Accounting Review, 40(3) 558568.

48. Hyvärinen, A. \& Oja, E. (2000). Independent component analysis: algorithms and applications. Neural Networks, 13(4-5) 411-430.

49. Jarque, C.M. \& Bera, A.K. (1987). A test for normality of observations and regression residuals. 
International Statistical Review, 55(2) 163-172.

50. Kalman, R.E. (1960). A new approach of linear filtering and prediction problems. Transaction of the ASME - Journal of Basic Engineering, 82(1) 35-45.

51. Karunanayake, I., Valadkhani, A. \& O'Brien, M. (2010). Financial crises and international stock market volatility transmission. Australian Economic Papers, 49(3) 209-221.

52. Kat, H.M. (2003). 10 Things investors should know about hedge funds. The Journal of Wealth Management, 5(4) 72-81.

53. Kolmogorov, A. N. (1933). Sulla determinazione empirica di une legge di distribuzione. Gior-nale dell'Intituto Italiano degli Attuari, 4 83-91.

54. Krokhmal, P., Palmquist, J. \& Uryasev, S. (2002). Portfolio optimization with conditional Value-at-Risk objective and constraints. Journal of risk, 4(2) 43-68.

55. Lamm, R. M. (2003). Asymmetric returns and optimal hedge fund portfolios. Journal of Alternative Investments, 6(2) 9-21.

56. Lhabitant, F.-S. (2004). Hedge funds: Quantitative insight. Haboken, NJ: Wiley. 354p.

57. Liang, B. \& Park, H. (2007). Risk measures for hedge funds: A cross-sectional approach. European financial management, 13(2) 333-370.

58. Lilliefors, H. W. (1967). On the Kolmogorov-Smimov test for normality with mean and variance unknown. Journal of the American Statistical Association, 62(318) 399-402.

59. Lin, J.-J., Saito, N. \& Levine, R. A. (1999). Edgeworth expansions of the Kullback-Leibler information. Working paper, Division of statistics, University of California, Davis, US. Technical report.

60. Linden, M. (2001). A model for stock return distribution. International Journal of Finance and Economics, 6(2) 159-169.

61. Lo, A. W. (2002). The statistics of Sharpe ratios. Financial Analysts Journal, 58(4) 36-52.

62. Markowitz, H. (1952). Portfolio selection. Journal of Finance, 7(1) 77-91.

63. McGregor BFA database. (2014). Supplier of data. [Web]: https://expert.mcgregorbfa.com/. [Date of access]: 10 January 2014.

64. Mcleay, S. \& Omar, A. (2000). The sensitivity of prediction models to the non-normality of bounded and unbounded financial ratios. British Accounting Review, 32(2) 213-230.

65. Moolman, E. \& Du Toit, C. (2005). An econometric model of the South African stock market. South African Journal of Economic and Management Sciences, 8(1) 77-91.

66. Nikkinen, J. \& Sahlström, P. (2004). Distributional properties and transformation of financial ratios: The impact of the accounting environment. Advances in International Accounting, 17 85-101.

67. Önder, A., Zaman, A. (2005). Robust tests for normality of errors in regression models. Economics Letters, 86(1) 63-68.

68. Overholt, B.A. (2013). A modified Lilliefors normality test. Creeley, Colorado: University of Northern Colorado. (Degree of Doctor of Philosophy). 95p.

69. Öztuna, D., Elhan, A.H. \& Tüccar, E. (2006). Investigation of four different normality tests in terms of Type 1 error rate and power under different distributions. Turkish Journal of Medical Sciences, 36(3) 171176.

70. Pearson, K. (1900). On the criterion that a given system of deviations from the probable in the case of a correlated system of variables is such that it can be reasonable supposed to have arisen from random sampling. Philosophical Magazine, 50 157-174.

71. Poitras, G. (2006). More on the correct use of omnibus tests for normality. Economic Letters, 90(3) 304309.

72. Poitras, G. (1992). Testing regression disturbances for normality with stable alternatives: Further Monte Carlo evidence. Journal of Statistical Computation and Simulation 41(1-2) 109-123.

73. Popova, I., Morton, D., \& Popova, E. (2003). Optimal hedge fund allocation with asymmetric preferences and distributions. Working paper, New York: Global research center, Deutsche asset management.

74. QMS (Quantitative Micro Software). (2009). EViews user guide 1”, Quantitative Micro Software.

75. Razali, N.M. \& Wah, Y.B. (2011). Power comparisons of Shapiro-Wilk, Kolmogorov-Smirnov, Lilliefors and Anderson-Darling tests. Journal of Statistical Modeling and Analystics, 2(1) 21-33.

76. Royston, P. (1991). Estimating departure from normality. Statistics in Medicine, 10(8) 1283-1293

77. Samouilhan, N. (2007). The price of risk in the South African equity market. South African Journal of Economics, 75(3) 442-458. 
78. SARB (South African Reserve Bank). (2010). Financial stability review, September 2010, South African Reserve Bank. 45p.

79. Schwert, G.W. (1989). Business cycles, financial crises, and stock volatility. Carnegie-Rochester Conference Series on Public Policy, 31 83-126.

80. Seier, E. (2002). Comparison of tests for univariate normality. InterStat Statistical Journal,1 1-17.

81. Shapiro, S.S. \& Wilk, M.B. (1965). An analysis of variance test for normality (Complete samples). Biometrika, 52(3/4) 591-611.

82. Sharpe, F.A. (1994). The Sharpe ratio. Journal of Portfolio Management, 21(1) 49-58.

83. Sharpe, W. F. (1966). Mutual fund performance. Journal of Business, 39(1) 119-138.

84. Smirnov, N. (1939). Sur les Ecarts de la Courbe de Distribution Empirique. Recueil Mathematique (Matematiceskii Sbornik), 6(48) 3-26.

85. Sortiono, F.A. \& Prince, L. (1994). Performance measurement in a downside risk framework. Journal of Investing, 3(3) 59-64

86. Stephens, M.A. (1974). EDF statistics for goodness of fit and comparisons. Journal of the American Statistical Association, 69(347) 730-737.

87. Stephens, M.A. (1981). Asymptotic power of EDF statistic for exponentiality against Gamma and Weibull alternatives. Working paper, Technical report no. 297.

88. Stephens, M.A. (1977). Goodness of fit for the extreme value distribution. Biometrika, 64(3) 585-588.

89. Steyn, A.G.W., Smit, C.F., Du Toit, S.H.C. \& Strasheim, C. (1998). Moderne statistiek vir die praktyk. Pretoria: Van Schaik. 761p.

90. Tarongi, J.M. \& Camps, A. (2010). Normality analysis for RFI detection in microwave radiometry. Remote Sensing, 2(1) 191-210.

91. Taylor, S.J. (1986). Modelling financial time series. London: Wiley. 268p.

92. Terhaar, K., Staub, R., \& Singer, B. (2003). Appropriate policy allocation for alternative investments: A factor approach and simulation techniques. Journal of Portfolio Management, 29(3) 101-110.

93. Thode, H. C. (2002). Testing for normality. New York: Marcel Dekker. 479p.

94. Thadewald, T. \& Büning, H. (2007). Jarque-Bera test and its competitors for testing normality - A Power Comparison. Journal of Applied Statistics, 34(1) 87-105.

95. Trujillo-Ortiz, A., Hernandez-Walls, R., Barba-Rojo, K. \& Castro-Perez, A. (2007). AnDartest:AndersonDarling test for assessing normality of a sample data. Retrieve from http://www.mathworks.com/matlabcentral/fileexchange/14807-andartest.

96. Urzúa, C. (1996). On the correct use of omnibus tests for normality. Economics Letters 53(3) 247-251.

97. Van Dyk, F., Van Vuuren, G. \& Heymans, A. (2014). Hedge fund performance using scaled Sharpe and Treynor measures. International business \& economic research journal, forthcoming.

98. Van Es, B. (1992). Estimating functionals related to a density by a class of statistics based on spacings. Scandinavian Journal of Statistics, 19(1) 61-72.

99. Vasicek, O. (1976). A test for normality based on sample entropy. Journal of the RoyalStatistical Society, 38(1) 54-59.

100. Von Mises, R. (1931). Wahrscheinlichkeitsrechnung und ihre anwendung in der statistik and theoretischen Physik. Deuticke: Leipzig. 574p.

101. Wong, W.K., Phoon, K. F., \& Lean, H. H. (2008). Stochastic dominance analysis of Asian hedge funds. Pacific-Basin Financial Journal, 16(3) 204-223.

102. Wong, W.K. \& Sim, C.H. (2000). Goodness-of-fit test based on empirical characteristic function. Journal of Statistical Computation and Simulation, 65(1-4) 243-269.

103. Yap, B.W. \& Sim, C.H. (2011). Comparisons of various types of normality tests. Journal of Statistical Computation and Simulations, 81(12) 2141-2155.

104. Yazici, B. \& Yolacan, S. (2007). A comparison of various tests of normality. Journal of Statistical Computation and Simulation, 77(2) 175-183. 


\section{APPENDIX}

Table A: Summary Of Four Moments And Test For Normality

\begin{tabular}{|c|c|c|c|c|c|c|c|c|c|c|c|c|c|c|c|c|c|c|}
\hline & \multicolumn{9}{|c|}{ ENTIRE SAMPLE (DAILY FREQUENCY) } & \multicolumn{9}{|c|}{ ENTIRE SAMPLE (WEEKLY FREQUENCY) } \\
\hline & Mean & Std. Dev. & Skew. & Kurt. & JB & CVM & AD & KS & SW & Mean & Std. Dev. & Skew. & Kurt. & JB & CVM & $\mathbf{A D}$ & KS & SW \\
\hline $\begin{array}{c}\text { 1-month } \\
\text { JIBAR }\end{array}$ & 0.000 & 0.000 & 0.817 & 2.467 & $276.918^{*}$ & $15.977^{*}$ & $97.813^{*}$ & $0.179^{*}$ & $0.873^{*}$ & 0.001 & 0.000 & 0.805 & 2.427 & 57.494* & $3.381 *$ & $20.721 *$ & $0.193 *$ & $0.847^{*}$ \\
\hline $\begin{array}{l}\text { 3-month } \\
\text { JIBAR }\end{array}$ & 0.000 & 0.000 & 0.802 & 2.490 & $265.834 *$ & $14.291 *$ & $90.135^{*}$ & $0.157^{*}$ & $0.879 *$ & 0.001 & 0.000 & 0.790 & 2.452 & $55.185^{*}$ & $3.029^{*}$ & $19.110^{*}$ & $0.169^{*}$ & $0.854^{*}$ \\
\hline $\begin{array}{c}\text { 6-month } \\
\text { JIBAR }\end{array}$ & 0.000 & 0.000 & 44.082 & 2040.178 & $390 \times 10^{9} *$ & $98.708^{*}$ & $507.111^{*}$ & $0.394 *$ & $0.078 *$ & 0.001 & 0.000 & 0.848 & 2.593 & 59.994* & $2.950^{*}$ & $18.478^{*}$ & $0.172 *$ & $0.857^{*}$ \\
\hline $\begin{array}{c}\text { 9-month } \\
\text { JIBAR }\end{array}$ & 0.000 & 0.000 & 0.884 & 2.751 & $298.895^{*}$ & $12.819^{*}$ & $79.962 *$ & $0.129 *$ & $0.891^{*}$ & 0.001 & 0.000 & 0.874 & 2.717 & $61.734 *$ & $2.709^{*}$ & $16.878^{*}$ & $0.147 *$ & $0.865^{*}$ \\
\hline $\begin{array}{l}\text { 12-month } \\
\text { JIBAR }\end{array}$ & 0.000 & 0.000 & 0.890 & 2.820 & $300.152^{*}$ & $11.613^{*}$ & $73.249^{*}$ & $0.120^{*}$ & $0.898^{*}$ & 0.001 & 0.000 & 0.882 & 2.795 & $62.104 *$ & $2.441^{*}$ & $15.414 *$ & $0.133 *$ & $0.873^{*}$ \\
\hline R157 & 0.000 & 0.000 & -0.378 & 2.867 & 55.104* & $6.827 *$ & $38.657^{*}$ & $0.102^{*}$ & $0.958^{*}$ & 0.001 & 0.000 & -0.380 & 2.852 & 11.803* & $1.437 *$ & $8.207^{*}$ & 0.101* & $0.958^{*}$ \\
\hline R186 & 0.000 & 0.000 & 0.293 & 3.022 & $32.320^{*}$ & $0.607^{*}$ & $5.695^{*}$ & $0.046^{*}$ & $0.985^{*}$ & 0.002 & 0.000 & 0.290 & 2.994 & $6.651^{*}$ & $0.156^{*}$ & $1.437^{*}$ & $0.041 * *$ & $0.986^{*}$ \\
\hline $\begin{array}{l}\text { 1-to-3 year } \\
\text { bond index }\end{array}$ & 0.000 & 0.003 & 1.392 & 357.938 & $\begin{array}{c}11811 \\
423.000^{*}\end{array}$ & $53.640^{*}$ & $291.679^{*}$ & $0.223^{*}$ & $0.309^{*}$ & 0.000 & 0.004 & -2.708 & 76.739 & $\begin{array}{c}107 \\
741.000 * \\
\end{array}$ & $4.679^{*}$ & $28.379^{*}$ & $0.152^{*}$ & $0.607^{*}$ \\
\hline $\begin{array}{l}\text { 3-to-7 year } \\
\text { bond index }\end{array}$ & 0.000 & 0.006 & 2.391 & 271.317 & $6751590.000 *$ & $48.401^{*}$ & $270.586^{*}$ & $0.209^{*}$ & $0.337^{*}$ & 0.000 & 0.008 & 1.642 & 40.040 & $27251.840 *$ & $3.482^{*}$ & $21.951^{*}$ & $0.146^{*}$ & $0.714^{*}$ \\
\hline $\begin{array}{l}12+\text { month } \\
\text { bond index }\end{array}$ & 0.000 & 0.006 & -0.167 & 4.928 & $358.862^{*}$ & $1.796^{*}$ & $10.524 *$ & $0.050^{*}$ & $0.980 *$ & 0.000 & 0.012 & 0.306 & 4.725 & $66.025 *$ & $0.291^{*}$ & $1.747^{*}$ & $0.046^{*}$ & $0.980^{*}$ \\
\hline $\begin{array}{c}\text { JSE All } \\
\text { Share }\end{array}$ & 0.001 & 0.013 & -0.101 & 6.523 & $1167.566^{*}$ & $3.093 *$ & $19.082 *$ & $0.059 *$ & $0.957^{*}$ & 0.003 & 0.022 & -0.225 & 5.028 & $85.072 *$ & $0.523 *$ & $3.149 *$ & $0.063 *$ & $0.978^{*}$ \\
\hline JSE Top 40 & 0.001 & 0.014 & -0.031 & 6.431 & 1 1 103.777* & $2.975^{*}$ & $18.225^{*}$ & $0.057^{*}$ & $0.959^{*}$ & 0.003 & 0.024 & -0.146 & 5.275 & $103.662 *$ & $0.525^{*}$ & $3.113^{*}$ & $0.065 *$ & $0.978^{*}$ \\
\hline JSE Bank & 0.001 & 0.017 & 0.142 & 5.388 & $542.197^{*}$ & $1.967^{*}$ & $12.247^{*}$ & $0.050^{*}$ & $0.974 *$ & 0.002 & 0.027 & -0.123 & 4.536 & $47.685^{*}$ & $0.214^{*}$ & $1.462 *$ & $0.043 * *$ & $0.983^{*}$ \\
\hline $\begin{array}{c}\text { JSE } \\
\text { Financials } \\
\end{array}$ & 0.000 & 0.013 & 0.062 & 6.097 & $900.358^{*}$ & $2.959 *$ & $18.078^{*}$ & $0.058^{*}$ & $0.963^{*}$ & 0.002 & 0.021 & -0.414 & 5.005 & $92.724 *$ & $0.174 *$ & $1.300^{*}$ & $0.046^{*}$ & $0.984 *$ \\
\hline $\begin{array}{c}\text { JSE } \\
\text { Industrials }\end{array}$ & 0.001 & 0.011 & -0.119 & 5.500 & $591.090^{*}$ & $1.580^{*}$ & $10.158^{*}$ & $0.044^{*}$ & $0.975 *$ & 0.003 & 0.020 & -0.479 & 3.700 & $27.705^{*}$ & $0.168^{*}$ & $1.152^{*}$ & $0.044 *$ & $0.985^{*}$ \\
\hline AGL & 0.001 & 0.025 & 0.161 & 31 & $1850.071^{*}$ & $2.671^{*}$ & $17.508^{*}$ & 5* & $0.952^{*}$ & 0.002 & 0.043 & -0.241 & 5.300 & $108.802^{*}$ & $0.411^{*}$ & $2.776^{*}$ & $0.052 *$ & $0.977^{*}$ \\
\hline BIL & 0.001 & 0.023 & 0.507 & 8.311 & $2740.582 *$ & $2.734 *$ & $17.317^{*}$ & $0.057^{*}$ & $0.950^{*}$ & 0.004 & 0.040 & 0.662 & 10.121 & $1033.781 *$ & $0.272^{*}$ & $2.105^{*}$ & 0.035 & $0.981^{*}$ \\
\hline CFR & & & .832 & 55.541 & $261812.200^{*}$ & $3917 *$ & $23.159^{*}$ & $0.063^{*}$ & $0.878^{*}$ & 000 & & -1.836 & 14.520 & $2881.002 *$ & $0.635^{*}$ & $4.154 *$ & $0.044 *$ & $0.958^{*}$ \\
\hline FSR & 0.001 & 0.021 & -0.066 & 4.980 & $369.105^{*}$ & $0.988^{*}$ & $5.863^{*}$ & $0.034^{*}$ & $0.984^{*}$ & 0.003 & 0.032 & -0.367 & 4.841 & 77.388* & $0.133^{*}$ & $1.211^{*}$ & 0.033 & $0.986^{*}$ \\
\hline MTN & 0.001 & & 0.474 & 6.721 & $1382.185^{*}$ & $1.798^{*}$ & $11.067^{*}$ & $0.049^{*}$ & $0.966^{*}$ & 0.004 & & 0.223 & 4.201 & $32.334 *$ & $0.335^{*}$ & $1.889^{*}$ & $0.046 *$ & $0.987^{*}$ \\
\hline NPN & 0.001 & 0.021 & 0.022 & 4.129 & $119.756^{*}$ & $1.037 *$ & $5.597^{*}$ & $0.038^{*}$ & $0.991^{*}$ & 0.00 & 0.031 & -0.158 & 3.257 & 3.269 & 0.057 & 0.361 & 0.034 & 0.995 \\
\hline OML & 0.001 & 0.023 & -0.002 & 10.699 & $5556.656 *$ & $6.337 *$ & $38.876^{*}$ & $0.088^{*}$ & $0.907^{*}$ & 0.002 & & -0.235 & 7.439 & $392.634 *$ & $0.910^{*}$ & $5.567 *$ & $0.072 *$ & $0.941^{*}$ \\
\hline SAB & 0.001 & 0.016 & 0.248 & 5.791 & 753.182* & $1.300^{*}$ & $7.898^{*}$ & $0.047^{*}$ & $0.975^{*}$ & 0.00 & 0.025 & 0.004 & 4.111 & $24.337^{*}$ & $0.139^{*}$ & 0.993* & $\begin{array}{l}0.046 * \\
\end{array}$ & $0.990^{*}$ \\
\hline SBK & 0.000 & 0.019 & 0.230 & 5.643 & 674.558* & $2.254^{*}$ & $13.436^{*}$ & $0.052^{*}$ & $0.972^{*}$ & 0.002 & 0.029 & 0.323 & 6.410 & $237.445^{*}$ & $0.292 *$ & \begin{tabular}{|l|}
$1.720^{*}$ \\
\end{tabular} & 0.049* & $0.963^{*}$ \\
\hline SOL & 0.00 & 0.022 & 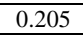 & & $1045.955^{*}$ & $2519 *$ & $15.336 *$ & $0.055^{*}$ & $0.963^{*}$ & 0.00 & & -0.356 & 5.430 & $126.349^{*}$ & $0.260^{*}$ & $1.626^{*}$ & $0.048 *$ & $0.975^{*}$ \\
\hline BGA & 0.000 & 0.019 & 0.250 & 5.695 & $704.657^{*}$ & $2.831^{*}$ & $16.224 *$ & $0.064^{*}$ & $0.969^{*}$ & 0.002 & 0.030 & -0.101 & 4.178 & $28.173^{*}$ & $0.273^{*}$ & $1.817^{*}$ & $0.055^{*}$ & $0.986^{*}$ \\
\hline SLM & & & & & & & $21220 \%$ & 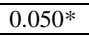 & $0974 *$ & 0.003 & (2) & & 4.0 & $24.870^{*}$ & $0.254^{*}$ & $1.643 *$ & $0.046 *$ & $0.989^{*}$ \\
\hline APN & 0.001 & 0.020 & 0.157 & 5.289 & $500.389^{*}$ & $2.909 *$ & $16.345^{*}$ & $0.059^{*}$ & $0.971^{*}$ & 0.006 & 0.034 & 0.559 & 4.767 & $86.204 *$ & $0.328^{*}$ & $2.278^{*}$ & $0.053 *$ & $0.970^{*}$ \\
\hline AMS & 0.001 & 0.027 & -0.151 & 5.526 & $606.907 *$ & $2.073^{*}$ & $12.509^{*}$ & $0.050^{*}$ & $0.973^{*}$ & 0.003 & 0.048 & -0.210 & 5.000 & $82.285^{*}$ & $0.293^{*}$ & \begin{tabular}{|l|}
$1.859^{*}$ \\
\end{tabular} & $0.042 * *$ & $0.983^{*}$ \\
\hline ZAR/EUR & 0.000 & 0.010 & 1.881 & 31.758 & $78858.490^{*}$ & $4.698^{*}$ & $27.236^{*}$ & $0.074^{*}$ & $0.892^{*}$ & 0.001 & 0.017 & 0.698 & 5.420 & $153.891^{*}$ & $0.661^{*}$ & \begin{tabular}{|l|l|}
$4.112^{*}$ \\
\end{tabular} & $0.062 *$ & $0.969^{*}$ \\
\hline ZAR/GBP & 0.000 & 0.010 & 1.441 & 25.478 & $070^{*}$ & $3.256^{*}$ & $19.939^{*}$ & $0.060^{*}$ & $0.912^{*}$ & 0.001 & 0.017 & 0.255 & 5.107 & $87.938^{*}$ & $0.352 *$ & $2.388^{*}$ & $0.051 *$ & $0.979^{*}$ \\
\hline ZAR/USD & 0.000 & 0.012 & 1.689 & 26.778 & $54073.270^{*}$ & $3.656^{*}$ & $21.451^{*}$ & $0.069^{*}$ & $0.908^{*}$ & 0.001 & 0.018 & 0.745 & 5.234 & $134.525^{*}$ & $0.177^{*}$ & $1.315^{*}$ & 0.038 & $0.972^{*}$ \\
\hline $\begin{array}{c}\text { Kruger } \\
\text { Rand }\end{array}$ & 0.001 & 0.019 & 0.449 & 9.016 & $3468.009 *$ & $43.327^{*}$ & $197.107^{*}$ & $0.265^{*}$ & $0.799 *$ & 0.004 & 0.022 & 0.477 & 4.930 & 91.343* & $0.762 *$ & $3.996 *$ & $0.073^{*}$ & $0.970^{*}$ \\
\hline
\end{tabular}


The Journal of Applied Business Research - January/February 2015

Volume 31, Number 1

\begin{tabular}{|c|c|c|c|c|c|c|c|c|c|c|c|c|c|c|c|c|c|c|}
\hline & \multicolumn{9}{|c|}{ ENTIRE SAMPLE (MONTHLY FREQUENCY) } & \multicolumn{9}{|c|}{ PRE-FINANCIAL CRISIS PERIOD (DAILY FREQUENCY) } \\
\hline & Mean & Std. Dev. & Skew. & Kurt. & JB & CVM & AD & $\mathbf{K S}$ & SW & Mean & Std. Dev. & Skew. & Kurt. & JB & CVM & AD & KS & SW \\
\hline $\begin{array}{l}\text { 1-month } \\
\text { JIBAR }\end{array}$ & 0.006 & 0.002 & 0.813 & 2.458 & $13.231 *$ & $0.763^{*}$ & $4.666^{*}$ & $0.176^{*}$ & $0.873^{*}$ & 0.000 & 0.000 & 1.423 & 3.888 & $184.755^{*}$ & $10.001^{*}$ & $54.939^{*}$ & $0.301 *$ & $0.730^{*}$ \\
\hline $\begin{array}{c}\text { 3-month } \\
\text { JIBAR }\end{array}$ & 0.006 & 0.002 & 0.799 & 2.484 & $12.703^{*}$ & $0.686^{*}$ & $4.318^{*}$ & $0.158^{*}$ & $0.879^{*}$ & 0.000 & 0.000 & 1.312 & 3.486 & $148.162 *$ & $7.975^{*}$ & 44.824* & $0.244 *$ & $0.771^{*}$ \\
\hline $\begin{array}{c}\text { 6-month } \\
\text { JIBAR }\end{array}$ & 0.006 & 0.002 & 0.858 & 2.627 & $13.886^{*}$ & $0.670^{*}$ & $4.206^{*}$ & $0.157^{*}$ & $0.882 *$ & 0.000 & 0.001 & 22.230 & 495.796 & \begin{tabular}{|c|}
5090 \\
$305.000 *$ \\
\end{tabular} & $38.045^{*}$ & $179.589 *$ & $0.482 *$ & $0.031 *$ \\
\hline $\begin{array}{c}\text { 9-month } \\
\text { JIBAR }\end{array}$ & 0.006 & 0.002 & 0.886 & 2.747 & $14.410^{*}$ & $0.623^{*}$ & $3.892 *$ & $0.150^{*}$ & $0.889^{*}$ & 0.000 & 0.000 & 1.135 & 2.713 & $108.932 *$ & $9.256^{*}$ & 50.034* & $0.287^{*}$ & $0.765^{*}$ \\
\hline $\begin{array}{l}\text { 12-month } \\
\text { JIBAR }\end{array}$ & 0.006 & 0.002 & 0.893 & 2.819 & $14.486^{*}$ & $0.568^{*}$ & $3.587^{*}$ & $0.133^{*}$ & $0.896^{*}$ & 0.000 & 0.000 & 1.063 & 2.533 & 98.422* & $8.719^{*}$ & $47.430^{*}$ & $0.259^{*}$ & $0.776^{*}$ \\
\hline R157 & 0.006 & 0.001 & -0.405 & 2.838 & 3.068 & $0.363^{*}$ & $2.054 *$ & $0.124 *$ & $0.954 *$ & 0.000 & 0.000 & -0.015 & 2.173 & $14.233^{*}$ & \begin{tabular}{|l|l|}
$0.448^{*}$ \\
\end{tabular} & $3.782 *$ & \begin{tabular}{|l|}
$0.071 *$ \\
\end{tabular} & $0.971^{*}$ \\
\hline R186 & 0.007 & 0.001 & 0.283 & 2.858 & 1.536 & 0.052 & 0.420 & 0.065 & 0.982 & 0.000 & 0.000 & 0.388 & 2.462 & \begin{tabular}{|l}
$18.533^{*}$ \\
\end{tabular} & \begin{tabular}{|l|l|}
$0.645^{*}$ \\
\end{tabular} & $4.954 *$ & \begin{tabular}{|l|}
$0.070^{*}$ \\
\end{tabular} & $0.965^{*}$ \\
\hline $\begin{array}{l}\text { 1-to-3 year } \\
\text { bond index }\end{array}$ & -0.002 & 0.006 & 0.223 & 6.354 & $51.523 *$ & $0.365^{*}$ & $2.276^{*}$ & $0.105^{*}$ & $0.927^{*}$ & 0.000 & 0.001 & 0.293 & 7.007 & $340.974 *$ & $1.207^{*}$ & $6.752 *$ & $0.089^{*}$ & $0.945^{*}$ \\
\hline $\begin{array}{l}\text { 3-to-7 year } \\
\text { bond index }\end{array}$ & -0.001 & 0.013 & 0.181 & 7.260 & $82.262 *$ & $0.341^{*}$ & $2.228^{*}$ & $0.106^{*}$ & $0.916^{*}$ & 0.000 & 0.002 & 0.037 & 5.171 & 98.117* & $0.568 *$ & $3.419 *$ & $0.061^{*}$ & $0.972 *$ \\
\hline $\begin{array}{l}12+\text { month } \\
\text { bond index }\end{array}$ & -0.001 & 0.026 & 0.161 & 4.381 & $9.050^{*}$ & $0.136^{*}$ & $0.762^{*}$ & 0.073 & $0.979 * *$ & 0.000 & 0.006 & 0.252 & 4.305 & $40.695^{*}$ & $0.363 *$ & $2.268 *$ & $0.051^{*}$ & $0.982^{*}$ \\
\hline $\begin{array}{c}\text { JSE All } \\
\text { Share }\end{array}$ & 0.013 & 0.040 & -1.516 & 7.142 & $118.564 *$ & $0.423^{*}$ & $2.310^{*}$ & $0.134 *$ & $0.900 *$ & 0.001 & 0.011 & -0.446 & 7.159 & $376.219^{*}$ & $0.558^{*}$ & $3.875^{*}$ & $0.057 *$ & $0.950 *$ \\
\hline \begin{tabular}{|l|} 
JSE Top 40 \\
\end{tabular} & 0.013 & 0.042 & -1.452 & 6.857 & 104.909* & $0.387 *$ & $2.131^{*}$ & $0.132^{*}$ & $0.907 *$ & 0.001 & 0.012 & -0.337 & 6.911 & \begin{tabular}{|l|}
$327.486^{*}$ \\
\end{tabular} & \begin{tabular}{|l|}
$0.509 *$ \\
\end{tabular} & $3.544 *$ & \begin{tabular}{|l|}
$0.052^{*}$ \\
\end{tabular} & 0.954* \\
\hline JSE Bank & 0.010 & 0.046 & -0.450 & 3.508 & $4.809 * *$ & 0.062 & 0.431 & 0.049 & 0.983 & 0.001 & 0.017 & 0.118 & 5.276 & \begin{tabular}{|l|}
$108.880^{*}$ \\
\end{tabular} & \begin{tabular}{|l|}
$0.251 *$ \\
\end{tabular} & $1.633^{*}$ & \begin{tabular}{|l|}
$0.044 *$ \\
\end{tabular} & $0.979^{*}$ \\
\hline \begin{tabular}{c|} 
JSE \\
Financials \\
\end{tabular} & 0.009 & 0.040 & -0.715 & 4.359 & $17.518^{*}$ & $0.160^{*}$ & $0.891^{*}$ & $0.087^{*}$ & $0.969^{*}$ & 0.001 & 0.012 & -0.176 & 7.269 & $381.435^{*}$ & $0.565^{*}$ & $3.595 *$ & $0.060^{*}$ & $0.956^{*}$ \\
\hline \begin{tabular}{c|c} 
JSE \\
Industrials \\
\end{tabular} & 0.012 & 0.043 & -0.872 & 3.841 & $16.870^{*}$ & $0.250^{*}$ & $1.587^{*}$ & $0.104 *$ & $0.950^{*}$ & 0.001 & 0.012 & -0.426 & 4.868 & $87.646^{*}$ & $\mid 0.228 *$ & $1.473 *$ & $0.049 *$ & $0.981^{*}$ \\
\hline AGL & 0.007 & 0.078 & $\begin{array}{l}-0.477 \\
-0.45\end{array}$ & 4.290 & $11.575^{*}$ & 0.096 & 0.565 & 0.069 & 0.980 & 0.002 & 0.019 & 0.208 & 4.153 & $31.200^{*}$ & 0.101 & $0.751^{* *}$ & 0.027 & $0.990^{*}$ \\
\hline BIL & 0.017 & 0.069 & -0.269 & 3.799 & 4.178 & 0.073 & 0.431 & 0.063 & 0.987 & 0.002 & 0.019 & -0.075 & 3.514 & 5.954** & 0.082 & 0.516 & 0.034 & 0.996 \\
\hline CFR & 0.019 & 0.073 & -2.259 & 14.306 & $667.043^{*}$ & $0.705^{*}$ & $3.980^{*}$ & $0.170^{*}$ & $0.815^{*}$ & 0.002 & 0.016 & -0.290 & 7.971 & $520.658^{*}$ & \begin{tabular}{|l|}
$0.381 *$ \\
\end{tabular} & $2.524 *$ & \begin{tabular}{|l|}
$0.049^{*}$ \\
\end{tabular} & $0.955^{*}$ \\
\hline FSR & 0.010 & 0.056 & -0.755 & 3.355 & $10.837^{*}$ & $0.159^{*}$ & $1.150^{*}$ & $0.081^{* *}$ & $0.955^{*}$ & 0.001 & 0.020 & -0.005 & 4.334 & \begin{tabular}{|l|l|}
$36.994 *$ \\
\end{tabular} & $0.117 * *$ & $0.790 *$ & 0.039 ** & $0.989^{*}$ \\
\hline MTN & 0.016 & 0.056 & -0.232 & 3.199 & 1.142 & 0.039 & 0.246 & 0.045 & 0.993 & 0.002 & 0.023 & 0.206 & 3.834 & 18.014* & \begin{tabular}{|l|}
$0.139 *$ \\
\end{tabular} & $0.753 *$ & $0.038^{* * *}$ & $0.992^{*}$ \\
\hline NPN & 0.027 & 0.062 & -0.194 & 3.220 & 0.891 & 0.024 & 0.233 & 0.042 & 0.990 & 0.002 & 0.020 & -0.003 & 3.865 & \begin{tabular}{|l}
$15.575^{*}$ \\
\end{tabular} & \begin{tabular}{|l|}
$0.150 *$ \\
\end{tabular} & $0.892 *$ & 0.034 & $0.993^{*}$ \\
\hline OML & 0.009 & 0.075 & 0.134 & 5.628 & $31.404 *$ & 0.065 & 0.626 & 0.061 & $0.961 *$ & 0.001 & 0.016 & -0.288 & 5.219 & \begin{tabular}{|l|l|}
$109.222 *$ \\
\end{tabular} & \begin{tabular}{|l|}
$0.249 *$ \\
\end{tabular} & $1.663^{*}$ & \begin{tabular}{|l|l|}
$0.054^{*}$ \\
\end{tabular} & $0.978^{*}$ \\
\hline SAB & 0.017 & 0.043 & -0.647 & 4.133 & $13.322 *$ & 0.100 & $0.714 * *$ & 0.076 & $0.969^{*}$ & 0.001 & 0.014 & 0.733 & 6.787 & $342.839 *$ & \begin{tabular}{|l|}
$0.128^{*}$ \\
\end{tabular} & $0.873^{*}$ & 0.032 & $0.969^{*}$ \\
\hline SBK & 0.007 & 0.046 & -0.328 & 3.644 & 3.802 & 0.058 & 0.390 & 0.051 & 0.984 & 0.001 & 0.019 & 0.113 & 4.296 & \begin{tabular}{|l|l|}
$35.979 *$ \\
\end{tabular} & \begin{tabular}{|l|}
$0.227 *$ \\
\end{tabular} & $1.332 *$ & $0.040^{* * *}$ & $0.988^{*}$ \\
\hline SOL & 0.015 & 0.059 & -0.796 & 5.401 & $37.343 *$ & 0.093 & 0.571 & $0.091^{*}$ & $0.963^{*}$ & 0.002 & 0.022 & -0.159 & 4.642 & \begin{tabular}{|l|l|}
$58.182^{*}$ \\
\end{tabular} & \begin{tabular}{|l|}
$0.320 *$ \\
\end{tabular} & $1.970^{*}$ & \begin{tabular}{|l|l|}
$0.046^{*}$ \\
\end{tabular} & $0.981^{*}$ \\
\hline BGA & 0.007 & 0.054 & 0.040 & 3.225 & 0.257 & 0.065 & 0.394 & 0.071 & 0.990 & 0.001 & 0.018 & 0.454 & 6.598 & $286.252 *$ & \begin{tabular}{|l|l|}
$0.936^{*}$ \\
\end{tabular} & $4.952 *$ & $0.069^{*}$ & $0.958 *$ \\
\hline SLM & 0.014 & 0.048 & -0.280 & 2.928 & 1.435 & 0.050 & 0.309 & 0.053 & 0.991 & 0.001 & 0.018 & -0.184 & 4.299 & \begin{tabular}{|l}
$37.908^{*}$ \\
\end{tabular} & \begin{tabular}{|l|}
$0.189 *$ \\
\end{tabular} & $1.046 *$ & \begin{tabular}{|l|}
$0.053^{*}$ \\
\end{tabular} & $0.989^{*}$ \\
\hline APN & 0.027 & 0.066 & 0.027 & 2.990 & 0.014 & 0.096 & 0.494 & $0.085^{* * *}$ & 0.990 & 0.001 & 0.019 & 0.190 & 4.514 & \begin{tabular}{|l|l|}
$50.658^{*}$ \\
\end{tabular} & \begin{tabular}{|l|}
$0.829 *$ \\
\end{tabular} & $4.403 *$ & \begin{tabular}{|l|}
$0.074 *$ \\
\end{tabular} & $0.975^{*}$ \\
\hline AMS & 0.010 & 0.092 & -0.469 & 4.878 & 19.834* & $0.136^{*}$ & $0.834 *$ & $0.104 *$ & $0.970^{*}$ & 0.003 & 0.026 & 0.065 & 4.182 & 29.411* & \begin{tabular}{|l|l|}
$0.233^{*}$ \\
\end{tabular} & $1.489 *$ & \begin{tabular}{|l|l|}
$0.045^{*}$ \\
\end{tabular} & $0.987 *$ \\
\hline ZAR/EUR & 0.006 & 0.034 & 0.790 & 4.447 & $20.663 *$ & $0.180^{*}$ & $1.364 *$ & 0.078 & $0.953^{*}$ & 0.000 & 0.009 & 0.952 & 5.964 & 257.996* & \begin{tabular}{|l|l|}
$0.778^{*}$ \\
\end{tabular} & $4.273 *$ & \begin{tabular}{|l|}
$0.084 *$ \\
\end{tabular} & $0.952 *$ \\
\hline ZAR/GBP & 0.005 & 0.036 & 0.792 & 4.726 & $24.683^{*}$ & $0.159^{*}$ & $1.008^{*}$ & $0.092 *$ & $0.960^{*}$ & 0.001 & 0.009 & 0.879 & 5.431 & 187.160* & \begin{tabular}{|l|l|}
$0.554 *$ \\
\end{tabular} & $3.259 *$ & \begin{tabular}{|l|}
$0.070^{*}$ \\
\end{tabular} & $0.960^{*}$ \\
\hline ZAR/USD & 0.006 & 0.039 & 1.376 & 9.497 & $224.004 *$ & $0.131^{*}$ & $1.010^{*}$ & 0.070 & $0.916^{*}$ & 0.001 & 0.010 & 0.607 & 4.869 & 103.213* & \begin{tabular}{|l|}
$0.665^{*}$ \\
\end{tabular} & $3.919 *$ & \begin{tabular}{|l|}
$0.081 *$ \\
\end{tabular} & $0.967 *$ \\
\hline $\begin{array}{c}\text { Kruger } \\
\text { Rand }\end{array}$ & 0.016 & 0.048 & 0.900 & 5.662 & $46.477^{*}$ & $0.572^{*}$ & $3.155^{*}$ & $0.152^{*}$ & $0.916^{*}$ & 0.001 & 0.019 & 0.556 & 10.681 & $1252.352 *$ & $10.527^{*}$ & $48.726^{*}$ & $0.260^{*}$ & $0.765^{*}$ \\
\hline
\end{tabular}


The Journal of Applied Business Research - January/February 2015

Volume 31, Number 1

\begin{tabular}{|c|c|c|c|c|c|c|c|c|c|c|c|c|c|c|c|c|c|c|}
\hline & \multicolumn{7}{|c|}{ PRE-FINANCIAL CRISIS PERIOD (WEEKLY FREQUENCY) } & \multicolumn{11}{|c|}{ PRE-FINANCIAL CRISIS PERIOD (MONTHLY FREQUENCY) } \\
\hline & Mean & Std. Dev. & Skew. & Kurt. & JB & CVM & AD & KS & SW & Mean & Std. Dev. & Skew. & Kurt. & JB & CVM & AD & KS & SW \\
\hline $\begin{array}{l}\text { 1-month } \\
\text { JIBAR }\end{array}$ & 0.001 & 0.000 & 1.461 & 3.990 & $41.242 *$ & $2.123^{*}$ & $11.582^{*}$ & $0.316^{*}$ & $0.681 *$ & 0.006 & 0.000 & 1.466 & 4.002 & $9.604 *$ & $0.471^{*}$ & $2.563^{*}$ & $0.271^{*}$ & $0.737 *$ \\
\hline $\begin{array}{c}\text { 3-month } \\
\text { JIBAR }\end{array}$ & 0.001 & 0.000 & 1.348 & 3.567 & $32.877^{*}$ & $1.727^{*}$ & $9.612 *$ & $0.236^{*}$ & $0.737^{*}$ & 0.006 & 0.000 & 1.364 & 3.601 & $7.809^{*}$ & $0.394 *$ & $2.188^{*}$ & $0.225^{*}$ & $0.772 *$ \\
\hline $\begin{array}{c}\text { 6-month } \\
\text { JIBAR }\end{array}$ & 0.001 & 0.000 & 1.244 & 3.113 & $26.864 *$ & $1.741^{*}$ & $9.432 *$ & $0.240^{*}$ & $0.747^{*}$ & 0.006 & 0.001 & 1.244 & 3.119 & $6.201 *$ & $0.400 *$ & $2.166^{*}$ & \begin{tabular}{|l}
$0.273^{*}$ \\
\end{tabular} & $0.783^{*}$ \\
\hline \begin{tabular}{|c|} 
9-month \\
JIBAR
\end{tabular} & 0.001 & 0.000 & 1.156 & 2.752 & $23.425 *$ & $1.990^{*}$ & $10.691 *$ & $0.281^{*}$ & $0.717^{*}$ & 0.006 & 0.001 & 1.187 & 2.808 & $5.674 * *$ & $0.482 *$ & $2.573 *$ & $0.319^{*}$ & $0.753 *$ \\
\hline $\begin{array}{c}\text { 12-month } \\
\text { JIBAR }\end{array}$ & 0.001 & 0.000 & 1.082 & 2.572 & $21.077^{*}$ & $1.854^{*}$ & $10.047^{*}$ & $0.248^{*}$ & $0.736^{*}$ & 0.006 & 0.001 & 1.114 & 2.629 & $5.097^{* * *}$ & $0.454 *$ & $2.440^{*}$ & $0.295^{*}$ & $0.764 *$ \\
\hline R157 & 0.002 & 0.000 & -0.037 & 2.113 & 3.434 & $0.110^{* *}$ & $0.965 *$ & $0.094 * *$ & $0.965^{*}$ & 0.007 & 0.000 & -0.140 & 2.116 & 0.860 & 0.039 & 0.293 & 0.097 & 0.961 \\
\hline R186 & 0.001 & 0.000 & 0.391 & 2.441 & 4.003 & $0.150^{*}$ & $1.169^{*}$ & 0.076 & $0.962^{*}$ & 0.006 & 0.000 & 0.380 & 2.486 & 0.843 & 0.045 & 0.321 & 0.118 & 0.960 \\
\hline $\begin{array}{l}1 \text { 1-to-3 year } \\
\text { bond index }\end{array}$ & -0.001 & 0.002 & 0.576 & 6.475 & $58.091^{*}$ & $0.174 *$ & $1.115^{*}$ & $0.094^{* *}$ & $0.956^{*}$ & -0.003 & 0.004 & -0.535 & 3.009 & 1.144 & 0.051 & 0.341 & 0.113 & 0.961 \\
\hline $\begin{array}{r}\text { 3-to-7 year } \\
\text { bond index }\end{array}$ & -0.001 & 0.004 & 0.035 & 4.488 & $9.620^{*}$ & 0.098 & 0.595 & 0.061 & 0.985 & -0.003 & 0.009 & -0.536 & 3.186 & 1.184 & 0.039 & 0.295 & 0.113 & 0.959 \\
\hline $\begin{array}{l}12+\text { month } \\
\text { bond index }\end{array}$ & 0.000 & 0.010 & 0.076 & 3.162 & 0.215 & 0.080 & 0.483 & 0.073 & 0.985 & 0.001 & 0.024 & -0.187 & 2.565 & 0.330 & 0.020 & 0.128 & 0.082 & 0.988 \\
\hline $\begin{array}{c}\text { JSE All } \\
\text { Share }\end{array}$ & 0.007 & 0.020 & -0.506 & 4.440 & $13.428^{*}$ & $0.261^{*}$ & $1.492 *$ & $0.096^{* *}$ & 0.970* & 0.029 & 0.028 & -0.990 & 3.888 & $4.708^{* *}$ & 0.072 & 0.557 & 0.152 & $0.918^{* *}$ \\
\hline JSE Top 40 & 0.007 & 0.021 & -0.390 & 4.438 & $11.604 *$ & $0.238^{*}$ & $1.369^{*}$ & $0.089^{* *}$ & $0.969^{*}$ & 0.029 & 0.028 & -0.757 & 3.382 & 2.437 & 0.052 & 0.428 & 0.117 & 0.939 \\
\hline JSE Bank & 0.005 & 0.027 & 0.085 & 2.774 & 0.348 & 0.093 & 0.474 & $0.093^{* *}$ & 0.987 & 0.019 & 0.041 & -0.409 & 2.497 & 0.922 & 0.034 & 0.226 & 0.102 & 0.973 \\
\hline $\begin{array}{c}\text { JSE } \\
\text { Financials } \\
\end{array}$ & 0.005 & 0.019 & -0.144 & 2.650 & 0.890 & 0.066 & 0.413 & 0.072 & 0.984 & 0.022 & 0.033 & -0.645 & 2.692 & 1.759 & 0.068 & 0.468 & 0.111 & 0.946 \\
\hline $\begin{array}{c}\text { JSE } \\
\text { Industrials }\end{array}$ & 0.006 & 0.021 & -0.501 & 3.260 & $4.639^{* *}$ & 0.077 & 0.471 & 0.087 & 0.978 & 0.025 & 0.042 & -0.767 & 3.037 & 2.356 & 0.063 & 0.444 & 0.117 & 0.943 \\
\hline AGL & 0.010 & 0.034 & 0.146 & 4.503 & $10.161^{*}$ & 0.042 & 0.396 & 0.055 & $0.971 * *$ & 0.041 & 0.044 & 0.304 & 2.230 & 0.963 & 0.046 & 0.308 & 0.116 & 0.961 \\
\hline BIL & 0.007 & 0.030 & -0.228 & 3.413 & 1.640 & 0.062 & 0.442 & 0.065 & 0.990 & 0.031 & 0.058 & 0.410 & 2.450 & 0.974 & 0.069 & 0.438 & 0.134 & 0.949 \\
\hline CFR & 0.008 & 0.025 & -0.318 & 3.277 & 2.087 & 0.030 & 0.223 & 0.072 & 0.987 & 0.033 & 0.039 & 1.585 & 5.451 & $16.055^{*}$ & $0.168^{*}$ & $1.118^{*}$ & \begin{tabular}{|l|l|}
$0.179^{*}$ \\
\end{tabular} & $0.847^{*}$ \\
\hline FSR & 0.005 & 0.032 & 0.181 & 2.814 & 0.721 & 0.086 & 0.524 & 0.058 & 0.988 & 0.019 & 0.045 & -0.387 & 2.535 & 0.816 & 0.037 & 0.250 & 0.101 & 0.970 \\
\hline MTN & 0.007 & 0.036 & 0.114 & 3.454 & 1.118 & 0.054 & 0.346 & 0.056 & 0.989 & 0.029 & 0.058 & 0.206 & 3.216 & 0.217 & 0.034 & 0.224 & 0.093 & 0.982 \\
\hline NPN & 0.008 & 0.032 & 0.072 & 2.890 & 0.141 & 0.034 & 0.198 & 0.078 & 0.991 & 0.033 & 0.057 & -0.086 & 1.828 & 1.403 & 0.052 & 0.345 & 0.128 & 0.955 \\
\hline OML & 0.005 & 0.026 & 0.137 & 3.993 & 4.601 & $0.112 * *$ & 0.621 & 0.078 & 0.979 & 0.021 & 0.041 & -0.024 & 1.915 & 1.179 & 0.049 & 0.338 & 0.110 & 0.959 \\
\hline SAB & 0.005 & 0.023 & 0.705 & 4.321 & $16.191 *$ & $0.106^{* * *}$ & $0.736^{* * *}$ & 0.078 & $0.962^{*}$ & 0.021 & 0.030 & $\begin{array}{l}-0.371 \\
\end{array}$ & 2.517 & 0.784 & 0.030 & 0.248 & 0.087 & 0.966 \\
\hline SBK & 0.004 & 0.028 & 0.116 & 2.623 & 0.851 & 0.069 & 0.411 & 0.065 & 0.987 & 0.016 & 0.039 & -0.094 & 2.625 & 0.176 & 0.025 & 0.181 & 0.089 & 0.982 \\
\hline SOL & 0.008 & 0.039 & -0.332 & 3.153 & 2.011 & 0.031 & 0.212 & 0.041 & 0.992 & 0.035 & 0.054 & -0.007 & 1.991 & 1.018 & 0.037 & 0.259 & 0.092 & 0.966 \\
\hline BGA & 0.005 & 0.030 & -0.123 & 3.292 & 0.631 & 0.056 & 0.332 & 0.069 & 0.988 & 0.021 & 0.052 & -0.165 & 2.828 & 0.139 & 0.049 & 0.254 & 0.139 & 0.980 \\
\hline SLM & 0.004 & 0.027 & -0.060 & 3.134 & 0.140 & 0.049 & 0.339 & 0.047 & 0.990 & 0.016 & 0.050 & -0.016 & 2.314 & 0.472 & 0.018 & 0.169 & 0.081 & 0.975 \\
\hline APN & 0.006 & 0.036 & 0.643 & 4.033 & $11.795^{*}$ & 0.091 & $0.652 * *$ & 0.071 & $0.973 * *$ & 0.028 & 0.072 & -0.031 & 2.122 & 0.774 & 0.060 & 0.352 & 0.138 & 0.961 \\
\hline AMS & 0.015 & 0.049 & 0.507 & 5.511 & $31.763^{*}$ & 0.091 & 0.572 & $0.090^{* *}$ & $0.945^{*}$ & 0.062 & 0.055 & 1.008 & 4.144 & $5.373^{* * *}$ & 0.056 & 0.422 & 0.121 & $0.928^{* * *}$ \\
\hline ZAR/EUR & 0.002 & 0.015 & 0.850 & 4.314 & $20.000 *$ & $0.140 *$ & $0.990 *$ & $0.110^{*}$ & $0.963^{*}$ & 0.009 & 0.033 & 1.146 & 3.844 & $5.967^{* * *}$ & $0.139^{*}$ & \begin{tabular}{|l}
$0.929^{*}$ \\
\end{tabular} & $0.175^{* * *}$ & $0.888^{*}$ \\
\hline ZAR/GBP & 0.002 & 0.014 & 0.290 & 3.069 & 1.296 & 0.065 & 0.446 & 0.084 & 0.983 & 0.010 & 0.036 & 0.994 & 3.932 & $4.824^{* * *}$ & $0.117^{* *}$ & \begin{tabular}{|l}
$0.691 * *$ \\
\end{tabular} & \begin{tabular}{|l|l|}
$0.183^{*}$ \\
\end{tabular} & $0.917^{* *}$ \\
\hline ZAR/USD & 0.002 & 0.017 & 0.408 & 2.800 & 2.740 & 0.041 & 0.381 & 0.055 & 0.982 & 0.009 & 0.038 & 0.321 & 2.487 & 0.676 & 0.028 & 0.232 & 0.097 & 0.967 \\
\hline $\begin{array}{c}\text { Kruger } \\
\text { Rand }\end{array}$ & 0.006 & 0.018 & 0.680 & 3.590 & $9.519^{*}$ & $0.319^{*}$ & $1.715^{*}$ & $0.128^{*}$ & 0.946* & 0.026 & 0.035 & 1.898 & 7.138 & $31.536^{*}$ & $0.235^{*}$ & $1.343^{*}$ & $0.201^{*}$ & $0.817^{*}$ \\
\hline
\end{tabular}


The Journal of Applied Business Research - January/February 2015

Volume 31, Number 1

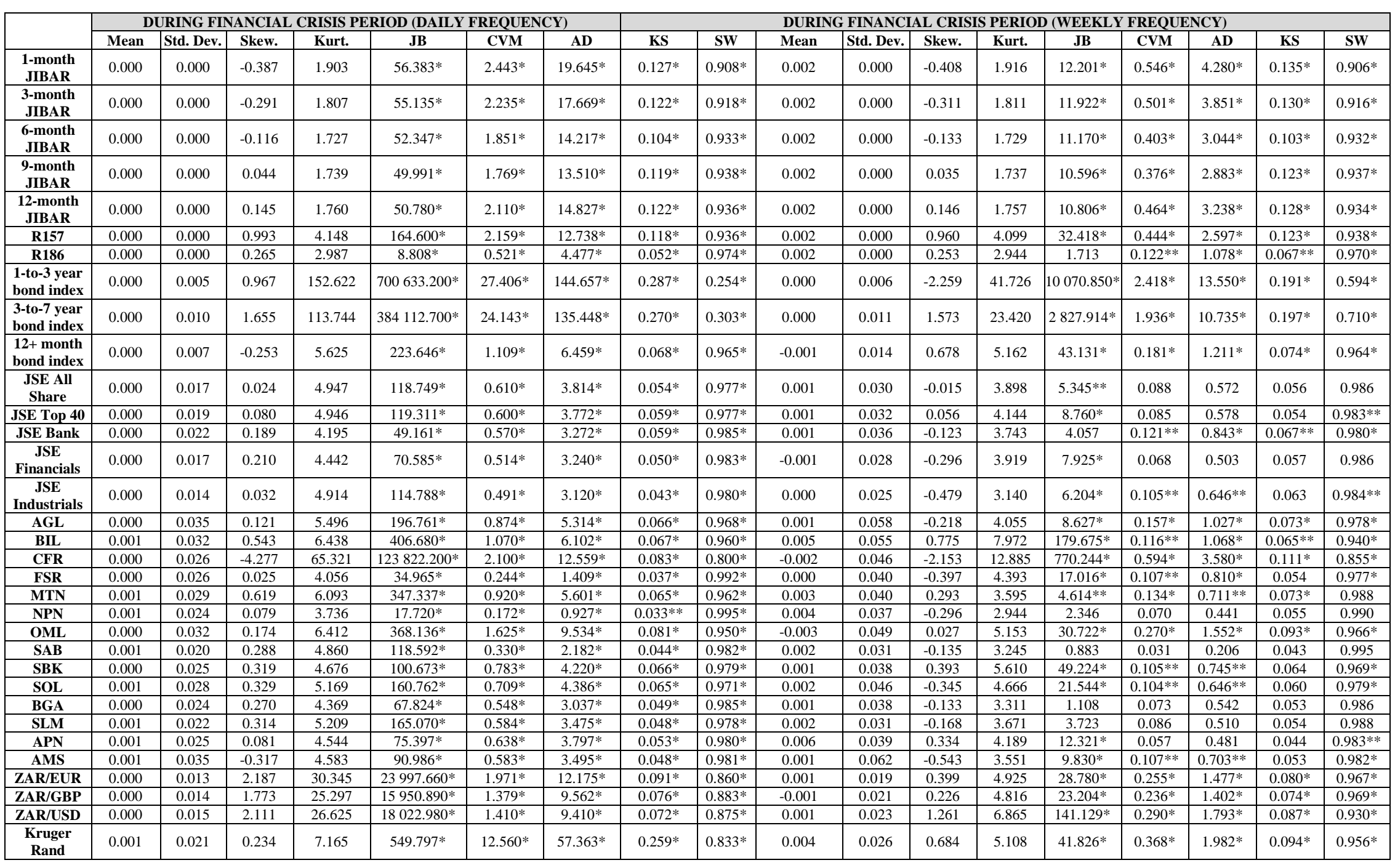


The Journal of Applied Business Research - January/February 2015

Volume 31, Number 1

\begin{tabular}{|c|c|c|c|c|c|c|c|c|c|c|c|c|c|c|c|c|c|c|}
\hline & \multicolumn{9}{|c|}{$\begin{array}{l}\text { DURING FINANCIAL CRISIS PERIOD (MONTHLY FREQUENCY) } \\
\text { (MANA }\end{array}$} & \multicolumn{9}{|c|}{ OST-FINANCIAL CRISIS PERIOD (DAILY FREQUENCY) } \\
\hline & Mean & Std. Dev. & Skew. & Kurt. & JB & CVM & AD & KS & SW & Mean & Std. Dev. & Skew. & Kurt. & JB & CVM & AD & KS & SW \\
\hline $\begin{array}{c}\text { 1-month } \\
\text { JIBAR }\end{array}$ & 0.008 & 0.001 & -0.392 & 1.910 & 2.703 & 0.117 ** & $0.927 *$ & $0.142^{* *}$ & $0.909 *$ & 0.000 & 0.000 & 1.173 & 3.512 & $240.318 *$ & $11.982^{*}$ & $67.810^{*}$ & $0.292^{*}$ & $0.819^{*}$ \\
\hline $\begin{array}{l}\text { 3-month } \\
\text { JIBAR }\end{array}$ & 0.008 & 0.001 & -0.292 & 1.802 & 2.663 & $0.111^{* *}$ & $0.869^{*}$ & $0.142^{* *}$ & $0.916^{*}$ & 0.000 & 0.000 & 1.269 & 3.743 & 291.413* & $13.927^{*}$ & 76.998* & $0.300^{*}$ & $0.796 *$ \\
\hline $\begin{array}{c}\text { 6-month } \\
\text { JIBAR }\end{array}$ & 0.008 & 0.001 & -0.115 & 1.710 & 2.576 & 0.095 & $0.729^{* *}$ & 0.111 & $0.929^{*}$ & 0.000 & 0.000 & 1.486 & 4.649 & $481.425^{*}$ & $11.472^{*}$ & $62.850^{*}$ & $0.272^{*}$ & $0.817^{*}$ \\
\hline $\begin{array}{c}\text { 9-month } \\
\text { JIBAR }\end{array}$ & 0.008 & 0.001 & 0.046 & 1.708 & 2.516 & 0.093 & $0.715^{* *}$ & 0.129 & $0.931 *$ & 0.000 & 0.000 & 1.394 & 4.489 & 416.066* & $9.140^{*}$ & $51.632^{*}$ & $0.224 *$ & $0.844 *$ \\
\hline $\begin{array}{c}\text { 12-month } \\
\text { JIBAR }\end{array}$ & 0.008 & 0.001 & 0.148 & 1.728 & 2.558 & $0.110^{* *}$ & $0.792 *$ & 0.139 ** & $0.928^{*}$ & 0.000 & 0.000 & 1.281 & 4.171 & $330.452 *$ & 7.354* & $43.890 *$ & $0.186^{*}$ & $0.862^{*}$ \\
\hline R157 & 0.007 & 0.001 & 1.000 & 3.823 & $7.014 *$ & $0.144 *$ & $0.880^{*}$ & $0.173^{*}$ & $0.916^{*}$ & 0.000 & 0.000 & 0.035 & 1.847 & $55.615^{*}$ & $1.595^{*}$ & $12.185^{*}$ & \begin{tabular}{|l|l|}
$0.089^{*}$ \\
\end{tabular} & $0.956^{*}$ \\
\hline R186 & 0.007 & 0.001 & 0.237 & 2.732 & 0.445 & 0.048 & 0.379 & 0.101 & 0.963 & 0.000 & 0.000 & -0.414 & 2.597 & $35.263^{*}$ & $1.120^{*}$ & \begin{tabular}{|l|l|}
$6.779^{*}$ \\
\end{tabular} & \begin{tabular}{|l|l|}
$0.061^{*}$ \\
\end{tabular} & $0.977^{*}$ \\
\hline $\begin{array}{l}\text { 1-to-3 year } \\
\text { bond index }\end{array}$ & -0.002 & 0.008 & 0.536 & 4.039 & 3.340 & $0.133^{*}$ & $0.735^{\text {** }}$ & $0.154^{*}$ & 0.953 & 0.000 & 0.001 & -0.393 & 8.061 & $1093.181 *$ & $2.244^{*}$ & $13.021^{*}$ & $0.082^{*}$ & $0.938 *$ \\
\hline $\begin{array}{l}\text { 3-to-7 year } \\
\text { bond index }\end{array}$ & -0.001 & 0.018 & 1.044 & 4.261 & $8.932^{*}$ & $0.256^{*}$ & $1.456^{*}$ & $0.191^{*}$ & $0.899^{*}$ & 0.000 & 0.003 & -0.632 & 6.547 & $590.792^{*}$ & $1.221 *$ & $7.231^{*}$ & $0.065^{*}$ & $0.961 *$ \\
\hline $\begin{array}{l}\text { 12+ month } \\
\text { bond index }\end{array}$ & -0.004 & 0.031 & 0.768 & 4.133 & $5.464 * *$ & $0.128 *$ & $0.719^{* *}$ & $0.154 *$ & $0.946^{* *}$ & 0.000 & 0.006 & -0.230 & 4.241 & $73.055^{*}$ & $0.500 *$ & $2.933^{*}$ & $0.052^{*}$ & $0.987 *$ \\
\hline $\begin{array}{c}\text { JSE All } \\
\text { Share }\end{array}$ & 0.005 & 0.056 & -1.228 & 4.695 & $13.363^{*}$ & $0.151^{*}$ & $0.905^{*}$ & $0.161^{*}$ & 0.903* & 0.001 & 0.010 & -0.155 & 4.281 & $72.349 *$ & $0.561 *$ & $3.478^{*}$ & $0.049 *$ & $0.986^{*}$ \\
\hline JSE Top 40 & 0.005 & 0.058 & -1.179 & 4.526 & $11.830^{*}$ & $0.137 *$ & $0.832^{*}$ & $0.146^{* * *}$ & $0.910^{*}$ & 0.001 & 0.011 & -0.104 & 4.214 & $63.166^{*}$ & \begin{tabular}{|l}
$0.564 *$ \\
\end{tabular} & $3.450^{*}$ & $0.051^{*}$ & $0.986^{*}$ \\
\hline JSE Bank & 0.003 & 0.062 & -0.300 & 2.632 & 0.744 & 0.053 & 0.380 & 0.094 & 0.967 & 0.001 & 0.013 & -0.027 & 4.203 & $60.393^{*}$ & \begin{tabular}{|l|}
$0.210^{*}$ \\
\end{tabular} & $1.515^{*}$ & 0.026 & $0.991^{*}$ \\
\hline $\begin{array}{c}\text { JSE } \\
\text { Financials } \\
\end{array}$ & -0.002 & 0.054 & -0.261 & 2.982 & 0.408 & 0.031 & 0.188 & 0.081 & 0.988 & 0.001 & 0.009 & -0.133 & 4.877 & $149.709 *$ & 0.546* & $3.458^{*}$ & 0.049* & $0.982^{*}$ \\
\hline $\begin{array}{c}\text { JSE } \\
\text { Industrials }\end{array}$ & 0.002 & 0.054 & -0.662 & 2.840 & 2.670 & $0.118^{* *}$ & $0.676^{* *}$ & 0.122 & 0.950 & 0.001 & 0.009 & -0.093 & 4.193 & $60.760^{*}$ & $0.338^{*}$ & $2.332 *$ & $0.040^{*}$ & $0.988 *$ \\
\hline AGL & 0.002 & 0.106 & -0.444 & 3.172 & 1.225 & 0.065 & 0.340 & 0.120 & 0.979 & 0.000 & 0.019 & 0.242 & 3.673 & $28.686^{*}$ & \begin{tabular}{|l|l|l}
$0.114^{* *}$ \\
\end{tabular} & $0.820^{*}$ & \begin{tabular}{|l|l|}
$0.029^{*}$ \\
\end{tabular} & $0.994 *$ \\
\hline BIL & 0.020 & 0.090 & -0.372 & 3.000 & 0.832 & 0.044 & 0.304 & 0.088 & 0.977 & 0.000 & 0.017 & 0.191 & 3.661 & $24.330^{*}$ & \begin{tabular}{|l|}
$0.130^{*}$ \\
\end{tabular} & $1.025^{*}$ & $0.029^{* *}$ & $0.994^{*}$ \\
\hline CFR & -0.007 & 0.100 & -2.163 & 9.219 & $86.081^{*}$ & $0.431 *$ & $2.461 *$ & $\begin{array}{l}0.218^{*} \\
\end{array}$ & $0.780^{*}$ & 0.002 & 0.018 & 0.092 & 4.814 & 138.573* & \begin{tabular}{|l|l|}
$0.817^{*}$ \\
\end{tabular} & $4.690^{*}$ & \begin{tabular}{|l|l|}
$0.051^{*}$ \\
\end{tabular} & $0.980^{*}$ \\
\hline FSR & -0.001 & 0.073 & -0.504 & 2.330 & 2.199 & 0.081 & 0.540 & 0.122 & $0.948^{* * *}$ & 0.001 & 0.016 & -0.291 & 5.015 & $183.258^{*}$ & \begin{tabular}{|l|}
$0.174 *$ \\
\end{tabular} & $0.978^{*}$ & \begin{tabular}{|l|}
$0.031^{*}$ \\
\end{tabular} & $0.987^{*}$ \\
\hline MTN & 0.013 & 0.070 & -0.393 & 2.353 & 1.554 & 0.050 & 0.335 & 0.088 & 0.969 & 0.001 & 0.017 & -0.017 & 3.902 & $33.947^{*}$ & 0.142 & $0.744 * *$ & $0.028^{* * *}$ & $0.994^{*}$ \\
\hline NPN & 0.021 & 0.076 & -0.416 & 2.841 & 1.074 & 0.030 & 0.261 & 0.071 & 0.970 & 0.001 & 0.018 & -0.044 & 4.043 & $45.623^{*}$ & $0.592 *$ & $3.297^{*}$ & $0.052 *$ & $0.989^{*}$ \\
\hline OML & -0.010 & 0.106 & 0.578 & 4.281 & 4.468 & 0.061 & 0.381 & 0.109 & 0.963 & 0.001 & 0.016 & -0.606 & 16.417 & $7561.785^{*}$ & 0.909* & $5.791 *$ & \begin{tabular}{|l|}
$0.060^{*}$ \\
\end{tabular} & $0.923^{*}$ \\
\hline SAB & 0.012 & 0.058 & -0.589 & 3.059 & 2.086 & 0.091 & 0.546 & 0.111 & 0.959 & 0.001 & 0.013 & -0.131 & 4.502 & $96.875^{*}$ & $0.447 *$ & $2.445^{*}$ & \begin{tabular}{|l|}
$0.041^{*}$ \\
\end{tabular} & $0.988^{*}$ \\
\hline SBK & 0.005 & 0.061 & -0.341 & 2.779 & 0.773 & 0.055 & 0.389 & 0.086 & 0.967 & 0.000 & 0.014 & -0.118 & 4.171 & $59.457 *$ & 0.194* & $1.543^{*}$ & $0.032 *$ & $0.990^{*}$ \\
\hline SOL & 0.007 & 0.076 & -0.816 & 4.484 & $7.298^{*}$ & 0.067 & 0.422 & 0.122 & 0.954 & 0.001 & 0.015 & 0.029 & 3.538 & $12.217^{*}$ & \begin{tabular}{|l|}
$0.156^{*}$ \\
\end{tabular} & $0.939^{*}$ & $0.027^{* * *}$ & $0.996^{*}$ \\
\hline BGA & 0.004 & 0.069 & 0.108 & 2.683 & 0.221 & 0.037 & 0.238 & 0.076 & 0.981 & 0.000 & 0.015 & -0.049 & 5.147 & $192.509 *$ & 0.637* & \begin{tabular}{|l|l|}
$3.784 *$ \\
\end{tabular} & \begin{tabular}{|l|}
$0.054 *$ \\
\end{tabular} & $0.980^{*}$ \\
\hline SLM & 0.008 & 0.059 & -0.162 & 2.469 & 0.580 & 0.022 & 0.151 & 0.066 & 0.987 & 0.001 & 0.014 & -0.012 & 4.559 & $101.236^{*}$ & $1.007^{*}$ & $5.670^{*}$ & $0.052^{*}$ & $0.980^{*}$ \\
\hline APN & 0.025 & 0.075 & -0.111 & 3.159 & 0.112 & 0.069 & 0.359 & 0.119 & 0.981 & 0.001 & 0.016 & 0.306 & 4.683 & $133.596 *$ & $0.747 *$ & $4.440 *$ & $0.051^{*}$ & $0.981^{*}$ \\
\hline AMS & 0.006 & 0.122 & -0.924 & 3.554 & $5.584^{* * *}$ & $0.204 *$ & $1.068 *$ & $0.167^{*}$ & $0.927^{*}$ & 0.000 & 0.020 & 0.274 & 4.015 & $55.418^{*}$ & $0.395^{*}$ & $2.229 *$ & \begin{tabular}{|l|}
$0.043^{*}$ \\
\end{tabular} & $0.990^{*}$ \\
\hline ZAR/EUR & 0.005 & 0.042 & 0.843 & 4.432 & $7.344 *$ & $0.125^{*}$ & $0.892 *$ & 0.122 & $0.929^{*}$ & 0.000 & 0.008 & 0.476 & 4.810 & $174.278^{*}$ & 0.657* & $4.331 *$ & $0.047^{*}$ & $0.978^{*}$ \\
\hline ZAR/GBP & -0.003 & 0.042 & 1.230 & 5.509 & $18.520^{*}$ & $0.125 * *$ & $0.804^{* * *}$ & 0.137 ** & $0.912 *$ & 0.000 & 0.008 & 0.247 & 4.135 & 63.908* & $0.565^{*}$ & $3.284 *$ & \begin{tabular}{|l|l|}
$0.046^{*}$ \\
\end{tabular} & $0.987 *$ \\
\hline ZAR/USD & 0.003 & 0.052 & 1.824 & 9.498 & $83.290^{*}$ & $0.199^{*}$ & $1.268^{*}$ & $\begin{array}{l}0.150^{*} \\
\end{array}$ & $0.849^{*}$ & 0.000 & 0.009 & 0.287 & 4.505 & $\begin{array}{l}108.170^{*} \\
\end{array}$ & \begin{tabular}{|l|}
$0.592 *$ \\
\end{tabular} & $3.487^{*}$ & \begin{tabular}{|l|l|}
$0.047 *$ \\
\end{tabular} & $0.984 *$ \\
\hline $\begin{array}{c}\text { Kruger } \\
\text { Rand }\end{array}$ & 0.019 & 0.062 & 0.759 & 4.373 & $6.284 *$ & $0.240 *$ & $1.266^{*}$ & $0.174 *$ & $0.922 *$ & 0.001 & 0.017 & 0.640 & 10.016 & 2 119.359* & $20.308^{*}$ & 91.525* & $0.275^{*}$ & $0.788^{*}$ \\
\hline
\end{tabular}


The Journal of Applied Business Research - January/February 2015

Volume 31, Number 1

\begin{tabular}{|c|c|c|c|c|c|c|c|c|c|c|c|c|c|c|c|c|c|c|}
\hline & \multicolumn{9}{|c|}{ POST-FINANCIAL CRISIS PERIOD (WEEKLY FREQUENCY) } & \multicolumn{9}{|c|}{ POST-FINANCIAL CRISIS PERIOD (MONTHLY FREQUENCY) } \\
\hline & Mean & Std. Dev. & Skew. & Kurt. & JB & CVM & AD & KS & SW & Mean & Std. Dev. & Skew. & Kurt. & JB & CVM & AD & KS & SW \\
\hline $\begin{array}{c}\text { 1-month } \\
\text { JIBAR }\end{array}$ & 0.001 & 0.000 & 1.190 & 3.557 & $52.262^{*}$ & $2.516^{*}$ & $14.289^{*}$ & $0.290^{*}$ & $0.817^{*}$ & 0.004 & 0.000 & 1.180 & 3.502 & $11.643^{*}$ & $0.567^{*}$ & $3.198^{*}$ & $0.285^{*}$ & $0.822 *$ \\
\hline $\begin{array}{c}\text { 3-month } \\
\text { JIBAR }\end{array}$ & 0.001 & 0.000 & 1.286 & 3.788 & $63.269^{*}$ & $2.912^{*}$ & $16.128^{*}$ & $0.301^{*}$ & $0.796^{*}$ & 0.005 & 0.000 & 1.278 & 3.739 & $14.159^{*}$ & $0.655^{*}$ & $3.613^{*}$ & $0.298^{*}$ & $0.801 *$ \\
\hline $\begin{array}{c}\text { 6-month } \\
\text { JIBAR }\end{array}$ & 0.001 & 0.000 & 1.498 & 4.697 & 103.766* & $2.428^{*}$ & $13.278^{*}$ & $0.276^{*}$ & $0.816^{*}$ & 0.005 & 0.000 & 1.491 & 4.600 & $22.914^{*}$ & $0.586^{*}$ & $3.167^{*}$ & $0.295^{*}$ & $0.815^{*}$ \\
\hline $\begin{array}{c}\text { 9-month } \\
\text { JIBAR }\end{array}$ & 0.001 & 0.000 & 1.402 & 4.523 & $89.140 *$ & $1.928^{*}$ & $10.898^{*}$ & $0.225^{*}$ & $0.842^{*}$ & 0.005 & 0.001 & 1.408 & 4.463 & $20.136^{*}$ & $0.465^{*}$ & $2.608^{*}$ & $0.225^{*}$ & $0.841^{*}$ \\
\hline $\begin{array}{c}\text { 12-month } \\
\text { JIBAR }\end{array}$ & 0.001 & 0.000 & 1.286 & 4.195 & $70.378^{*}$ & $1.548^{*}$ & $9.256^{*}$ & $0.186^{*}$ & $0.860^{*}$ & 0.005 & 0.001 & 1.299 & 4.162 & $16.204 *$ & $0.395^{*}$ & $2.312^{*}$ & $0.209^{*}$ & $0.855^{*}$ \\
\hline R157 & 0.001 & 0.000 & 0.038 & 1.832 & $11.986 *$ & $0.356^{*}$ & $2.734 *$ & $0.094 *$ & $0.953^{*}$ & 0.006 & 0.001 & 0.035 & 1.845 & 2.680 & 0.091 & $0.668^{* *}$ & 0.096 & $0.951 *$ \\
\hline R186 & 0.002 & 0.000 & $\begin{array}{l}-0.422 \\
\end{array}$ & $\begin{array}{l}2.574 \\
\end{array}$ & $7.819^{*}$ & $0.282^{*}$ & $1.737 *$ & $0.077 *$ & \begin{tabular}{|l|l|}
$0.973 *$ \\
\end{tabular} & 0.007 & 0.000 & $\begin{array}{l}-0.400 \\
\end{array}$ & 2.548 & 1.688 & 0.095 & 0.549 & \begin{tabular}{|l}
$0.121^{* * *}$ \\
\end{tabular} & 0.968 \\
\hline $\begin{array}{l}\text { 1-to-3 year } \\
\text { bond index }\end{array}$ & 0.000 & 0.002 & -0.596 & 5.329 & $59.926^{*}$ & $0.264 *$ & $1.674 *$ & $0.074 *$ & $0.963 *$ & -0.002 & 0.005 & -0.973 & 9.078 & $81.440^{*}$ & $0.140^{*}$ & $1.125^{*}$ & 0.114 & $0.879 *$ \\
\hline $\begin{array}{l}\text { 3-to-7 year } \\
\text { bond index }\end{array}$ & 0.000 & 0.005 & -0.977 & 5.625 & 93.733* & $0.386^{*}$ & $2.338^{*}$ & $0.101^{*}$ & $0.949 *$ & 0.000 & 0.011 & -2.398 & 14.013 & $288.586^{*}$ & $0.280^{*}$ & $1.796^{*}$ & $0.155^{*}$ & $0.798^{*}$ \\
\hline $\begin{array}{l}\text { 12+ month } \\
\text { bond index }\end{array}$ & 0.000 & 0.010 & -0.121 & 3.634 & 4.030 & $0.169^{*}$ & $0.923^{*}$ & $0.061^{* *}$ & $0.989 * *$ & 0.001 & 0.024 & -0.471 & 5.690 & $16.249^{*}$ & 0.083 & 0.618 & 0.087 & $0.942 *$ \\
\hline $\begin{array}{c}\text { JSE All } \\
\text { Share }\end{array}$ & 0.003 & 0.016 & -0.372 & 3.264 & $5.465^{* *}$ & $0.111^{* *}$ & $0.752 *$ & 0.056 & $0.985^{*}$ & 0.011 & 0.028 & -0.773 & 3.521 & $5.323 * *$ & $0.110^{* *}$ & $0.648^{* *}$ & 0.108 & $0.954 * *$ \\
\hline JSE Top 40 & 0.003 & 0.017 & -0.369 & 3.270 & $5.403 * *$ & $0.128^{*}$ & $0.810^{*}$ & $0.060^{* * *}$ & $0.985^{*}$ & 0.010 & 0.030 & -0.735 & 3.462 & $4.748 * *$ & $0.106 * *$ & $0.626 * *$ & 0.108 & $0.958^{* * *}$ \\
\hline JSE Bank & 0.002 & 0.019 & $\begin{array}{l}-0.050 \\
\end{array}$ & 2.581 & 1.624 & 0.043 & 0.287 & 0.035 & 0.993 & 0.010 & 0.033 & $\begin{array}{l}-0.135 \\
\end{array}$ & 2.179 & 1.493 & 0.048 & 0.330 & 0.085 & 0.978 \\
\hline $\begin{array}{c}\text { JSE } \\
\text { Financials }\end{array}$ & 0.003 & 0.014 & -0.102 & 2.650 & 1.435 & 0.024 & 0.225 & 0.028 & 0.992 & 0.012 & 0.027 & -0.531 & 3.316 & 2.459 & 0.065 & 0.403 & 0.095 & 0.975 \\
\hline $\begin{array}{c}\text { JSE } \\
\text { Industrials }\end{array}$ & 0.003 & 0.016 & -0.041 & 2.856 & 0.241 & 0.025 & 0.209 & 0.035 & 0.996 & 0.012 & 0.031 & -0.728 & 3.164 & 4.291 & 0.076 & $0.627 * *$ & 0.091 & $0.947^{*}$ \\
\hline AGL & -0.001 & 0.033 & -0.283 & 3.162 & 3.038 & 0.082 & 0.548 & 0.049 & 0.990 & -0.006 & 0.061 & 0.125 & 3.078 & 0.138 & 0.020 & 0.145 & 0.058 & 0.992 \\
\hline BIL & 0.002 & 0.029 & $\begin{array}{l}-0.139 \\
\end{array}$ & $\begin{array}{l}2.954 \\
\end{array}$ & 0.694 & 0.042 & 0.263 & 0.038 & 0.995 & 0.007 & 0.053 & $\begin{array}{l}-0.583 \\
\end{array}$ & 3.469 & 3.158 & 0.074 & 0.455 & 0.097 & 0.967 \\
\hline CFR & 0.007 & 0.029 & -0.059 & 2.941 & 0.152 & 0.059 & 0.385 & 0.039 & 0.994 & 0.032 & 0.056 & 0.034 & 3.519 & 0.548 & 0.061 & 0.327 & $0.120^{* *}$ & 0.987 \\
\hline FSR & 0.003 & 0.025 & $\begin{array}{l}-0.372 \\
\end{array}$ & 3.466 & $6.748^{*}$ & 0.031 & 0.310 & 0.030 & \begin{tabular}{|l|l|}
$0.987 *$ \\
\end{tabular} & 0.014 & 0.046 & $\begin{array}{l}-0.632 \\
\end{array}$ & 3.328 & 3.409 & 0.080 & 0.613 & 0.095 & $0.950^{*}$ \\
\hline MTN & 0.003 & 0.024 & 0.013 & 3.712 & 4.439 & $0.115^{* * *}$ & $0.663^{* *}$ & 0.053 & 0.990 & 0.012 & 0.040 & -0.256 & 2.237 & 1.689 & 0.073 & 0.495 & 0.100 & 0.965 \\
\hline NPN & 0.007 & 0.027 & 0.026 & 3.206 & 0.396 & 0.052 & 0.330 & 0.042 & 0.995 & 0.028 & 0.054 & 0.430 & 3.348 & 1.719 & 0.030 & 0.210 & 0.078 & 0.982 \\
\hline OML & 0.004 & 0.027 & -0.509 & 8.450 & $268.947^{*}$ & 0.099 & $0.782 *$ & 0.044 & \begin{tabular}{|l|}
$0.946^{*}$ \\
\end{tabular} & 0.017 & 0.056 & -0.046 & 2.333 & 0.907 & 0.027 & 0.184 & 0.066 & 0.984 \\
\hline SAB & 0.004 & 0.019 & 0.078 & 3.364 & 1.374 & 0.039 & 0.288 & 0.039 & 0.995 & 0.019 & 0.034 & 0.054 & 2.110 & 1.607 & 0.048 & 0.379 & 0.087 & 0.969 \\
\hline SBK & 0.001 & 0.020 & 0.063 & 3.209 & 0.521 & 0.019 & 0.122 & 0.029 & 0.998 & 0.005 & 0.033 & 0.011 & 2.309 & 0.956 & 0.034 & 0.277 & 0.069 & 0.979 \\
\hline SOL & 0.003 & 0.024 & -0.164 & 3.001 & 0.945 & 0.050 & 0.306 & 0.044 & 0.996 & 0.012 & 0.042 & -0.722 & 3.010 & 4.173 & $0.139 *$ & $0.787 *$ & $0.121 * *$ & $0.952 *$ \\
\hline BGA & 0.000 & 0.022 & 0.037 & $\begin{array}{l}4.531 \\
\end{array}$ & $20.558 *$ & 0.049 & 0.459 & 0.042 & \begin{tabular}{|l|}
$0.984 *$ \\
\end{tabular} & 0.001 & 0.041 & $\begin{array}{l}-0.079 \\
\end{array}$ & 2.940 & 0.057 & 0.031 & 0.232 & 0.071 & 0.987 \\
\hline SLM & 0.004 & 0.020 & $\begin{array}{l}-0.100 \\
\end{array}$ & 3.991 & $8.937^{*}$ & 0.076 & 0.610 & 0.051 & $0.988^{* * *}$ & 0.018 & 0.036 & -0.350 & 2.473 & 1.534 & 0.087 & 0.509 & 0.104 & 0.968 \\
\hline APN & 0.007 & 0.028 & 0.879 & 5.589 & $85.701 *$ & $0.280^{*}$ & $1.823^{*}$ & $0.080^{*}$ & \begin{tabular}{|l}
$0.953^{*}$ \\
\end{tabular} & 0.029 & 0.057 & 0.380 & 2.854 & 1.201 & 0.071 & 0.469 & 0.100 & 0.971 \\
\hline AMS & -0.003 & 0.034 & -0.050 & 3.629 & 3.543 & 0.064 & 0.437 & 0.045 & 0.991 & -0.013 & 0.071 & 1.378 & 7.529 & $56.218^{*}$ & $0.168^{*}$ & $1.031^{*}$ & \begin{tabular}{|l|l|}
$0.136^{*}$ \\
\end{tabular} & $0.902^{*}$ \\
\hline ZAR/EUR & 0.002 & 0.015 & 1.079 & 5.847 & 111.639* & $0.329^{*}$ & $1.982 *$ & $0.076^{*}$ & $0.946^{*}$ & 0.006 & 0.030 & 0.405 & 3.171 & 1.370 & 0.023 & 0.179 & 0.058 & 0.986 \\
\hline ZAR/GBP & 0.002 & 0.015 & 0.544 & 4.738 & $36.782^{*}$ & $0.172 *$ & $1.083^{*}$ & 0.052 & $0.975^{*}$ & 0.007 & 0.030 & 0.151 & 3.364 & 0.447 & 0.022 & 0.153 & 0.059 & 0.993 \\
\hline ZAR/USD & 0.002 & 0.017 & 0.741 & 5.078 & 57.004* & 0.071 & 0.593 & 0.045 & \begin{tabular}{|l|l|}
$0.969 *$ \\
\end{tabular} & 0.007 & 0.028 & 0.278 & 2.513 & 1.094 & 0.035 & 0.224 & 0.079 & 0.983 \\
\hline $\begin{array}{c}\text { Kruger } \\
\text { Rand }\end{array}$ & 0.002 & 0.021 & 0.110 & 3.579 & 3.354 & $0.146^{*}$ & $0.822 *$ & $0.057^{* *}$ & 0.989 & 0.010 & 0.040 & 0.700 & 4.593 & $8.998 *$ & $0.152^{*}$ & $0.933^{*}$ & $0.136^{*}$ & $0.945^{*}$ \\
\hline
\end{tabular}

Note: Std. Dev denotes standard deviation; Skew. denotes skewness; Kurt. denotes kurtosis; JB denotes Jarque-Bera; CVM denotes Cramer-von Mises; AD denotes Anderson-Darling; KS denotes Kolmogorov-Smirnov; SW denotes Shapiro-Wilk.

Note: * illustrate that the null hypothesis for normality is rejected at the 5\% level of significance; ** illustrate that the null hypothesis for normality is rejected at the $10 \%$ level of significance 